\title{
Postnatal developmental trajectory of sex-biased gene expression in the mouse pituitary
}

\section{gland}

Huayun Hou $^{1 *}$, Cadia Chan ${ }^{1,2,3^{*}}$, Kyoko E. Yuki ${ }^{1}$, Dustin Sokolowski ${ }^{1,2}$, Anna Roy ${ }^{1}$, Rihao Qu ${ }^{4,5}$, Liis Uusküla-Reimand ${ }^{1}$, Mariela Faykoo-Martinez ${ }^{1,6}$, Matt Hudson ${ }^{1,2}$, Christina Corre ${ }^{1,8,10}$, Anna Goldenberg ${ }^{1,7}$, Zhaolei Zhang ${ }^{2,7}$, Mark R. Palmert ${ }^{1,8,10, \#}$, Michael D. Wilson ${ }^{1,2, \#}$

(1) Genetics and Genome Biology, SickKids Research Institute, Toronto, ON, Canada

(2) Department of Molecular Genetics, University of Toronto, Toronto, ON, Canada

(3) Donnelly Centre for Cellular \& Biomolecular Research, Toronto, ON, Canada

(4) Interdepartmental Program of Computational Biology and Bioinformatics, Yale University, New Haven, CT, USA

(5) Department of Pathology, Yale School of Medicine, New Haven, CT, USA

(6) Department of Cell and Systems Biology, University of Toronto, Toronto, ON, Canada

(7) Department of Computer Science, University of Toronto, Toronto, ON, Canada

(8) Division of Endocrinology, The Hospital for Sick Children, Toronto, ON, Canada

(9) Institute of Medical Science, University of Toronto, Toronto, ON, Canada

(10) Departments of Pediatrics and Physiology, University of Toronto, Toronto, ON, Canada

*These authors contributed equally

\#Co-corresponding authors

\section{Abstract}

The pituitary gland controls sexually dimorphic processes such as growth, pubertal onset, and lactation. However, the mechanisms underlying sex biases in pituitary gene regulation are not fully understood. To capture pituitary gene regulation dynamics during postnatal development, we ascertained gene and miRNA expression across five postnatal days that span the pubertal transition in mice. Using 3'UTR-seq and small RNA sequencing, we observed over 900 instances of sex-biased gene expression, including 18 genes that were putative targets of 5 sexbiased miRNAs. In addition, by combining bulk RNA-seq with scRNA-seq pituitary data, we obtained evidence that cell-type proportion sex differences exist prior to puberty and contribute substantially to the observed sex-biased gene expression post-puberty. This work provides a resource for postnatal mouse pituitary gene regulation and highlights the importance of sex- 
biases in both cell-type composition and gene regulation when understanding the sexually dimorphic processes regulated by the pituitary gland.

\section{Introduction}

The pituitary gland plays a central role in regulating growth, lactation, reproduction, metabolism, stress responses, and puberty. These physiological processes are mediated by hormones released from five main anterior pituitary cell-types: growth hormone (GH) from somatotropes, prolactin (PRL) from lactotropes, follicle-stimulating hormone (FSH) and luteinizing hormone (LH) from gonadotropes, thyroid-stimulating hormone (TSH) from thryotropes, and adrenocorticotrophic hormone (ACTH) from corticotropes (Ooi et al., 2004). Non-hormone producing pituitary cells, including stem cells, and folliculostellate cells, are also present and support hormone-producing cells by functioning as progenitor cells and facilitating intercellular signaling within the pituitary (Fauquier et al., 2002; Yoshida et al., 2011).

Both pituitary hormone production and many physiological processes regulated by pituitary are sex-biased. For example, GH is secreted in a sexually different pattern in rodents more pulsatile in males compared to females, and regulates sex-biased gene expression in liver (Waxman and O'Connor, 2006). Moreover, the clinical presentation and prevalence of pituitaryrelated disorders can also differ between sexes. For example, the prevalence of prolactinoma is significantly higher in women, but men are more likely to present with macroadenomas (Agustsson et al., 2015; Mindermann and Wilson, 1994). While the sex differences in pitutiary function and diease are well known, the gene regulatory networks underlying these differences remain elusive. 
Several studies in rodents and humans have clearly highlighted sex differences in pituitary gland gene regulation. These studies include: targeted qPCR profiling of genes encoding for the main pituitary hormones in rat anterior pituitaries (Bjelobaba et al., 2015); serial analysis of gene expression (SAGE) in whole adult mouse pituitaries (Nishida et al., 2005a); and RNA-sequencing of adult human pituitaries as part of the Genotype-Tissue Expression (GTEx) project (Gershoni and Pietrokovski, 2017; Lopes-Ramos et al., 2020; Oliva et al., 2020). Most recently single-cell RNA-seq (scRNA-seq) has been performed in male and female adult mouse and rat pituitary glands revealing genes with sex-biased expression within specific cell-types (Fletcher et al., 2019; Ho et al., 2020; Ruf-Zamojski et al., 2021). While most gene expression studies have focussed on the adult pituitary, sex differences in pre-pubertal gene expression have been revealed using qPCR in mouse and rat pituitary glands (Bjelobaba et al., 2015; Hou et al., 2017) and by RNA-seq in juvenile mouse gonadotropes (Qiao et al., 2016). While these studies suggest that some sex differences in pituitary gene regulation are established prior to puberty we still lack a comprehensive view of pituitary gene regulation during postnatal development.

Another essential aspect of gene regulation is post-transcriptional regulation by microRNAs (miRNAs). While miRNA expression has been explored in pituitary glands of several mammalian species these studies were not focused on postnatal development in males and females (Bak et al., 2008; Bottoni et al., 2007; Ye et al., 2018; R.-S. Ye et al., 2015; Yuan et al., 2015; Zhang et al., 2018). While no evidence implicating miRNAs in sex-biased gene regulation in the pituitary has been reported, there are clear examples reported in the neonatal hypothalamus and pubertal liver (Hao and Waxman, 2018; Morgan and Bale, 2017).

The objective of this study was to characterize male and female pituitary gene expression during postnatal development and investigate the role of miRNAs in regulating pituitary sex 
differences. To achieve this, we profiled gene (3' untranslated region sequencing, 3'UTR-seq) and miRNA (small RNA sequencing, sRNA-seq) expression in male and female mice at multiple postnatal days spanning pubertal transition to identify genes and miRNAs exhibiting known or novel sex differences. The resulting temporal gene and miRNA expression data from this study can be queried and visualized at https://wilsonlab-sickkidsuoft.shinyapps.io/pituitary_gene_mirna_shiny/. Lastly, by leveraging single-cell RNA-seq (scRNA-seq) datasets, we provide evidence that sex differences in cell-type proportions emerge prior to the onset of puberty and likely contribute to sex-biases in bulk gene expression.

\section{Results}

\section{Profiling postnatal mouse pituitary gland development with 3'UTR-seq and small RNA-seq}

To assess changes in the mouse pituitary transcriptome across postnatal development, we profiled the pituitary RNA expression at five postnatal days (PD: 12, 22, 27, 32 and 37) that span mouse pubertal transition. We observed physical markers of pubertal onset, preputial separation (PS) and vaginal opening (VO) occurring on average at PD27 and PD29 in male and female mice respectively in our C57BL6/J colony ((Corre et al., 2016); Figure 1A). In all analyses performed, pubertal onset refers to ages at which PS and VO were recorded.

To measure mRNA expression in a genome-wide, cost-effective, and relatively highthroughput manner, we first automated the QuantSeq 3' mRNA-Seq protocol which profiles 3'UTR of mRNA transcripts (Materials and Methods and Supplementary figure S1A). We then profiled between 5 and 6 biological replicates for each sex at each of the five postnatal days (55 libraries total, see Supplementary table S1 for quality control metrics). 
It was shown previously that 3'UTR profiling could miss the expression of a gene if the gene annotation does not capture novel or tissue-specific 3'UTRs. For example, Propl expresses a novel 3'UTR in the pituitary and was missed in single-cell RNA-seq data generated using 10X technology (Cheung et al., 2018). To address this, we refined gene 3'-end annotations by identifying clusters of sequencing reads from our data and re-annotating 3'UTRs (Materials and Methods and Supplementary figure S1A). Improved pituitary-specific 3'UTR annotations were generated for 676 genes, allowing for assignment of significantly more reads to them, including important pituitary genes such as Poulfl, Ghrhr, Fshb, and Propl (Figure 1B, Supplementary figure S1B).

To profile miRNA expression, we performed sRNA-seq in the same male and female samples used for 3'UTR-seq (PD: 12, 22, 27, and 32; $n=5-6 ; 48$ libraries total). Using the miRDeep2 workflow, we identified 273 known mouse miRNAs (miRBase v21) and 19 novel miRNAs (Supplementary table S2 and Materials and Methods). The mature sequences of the novel miRNAs were used to identify homologous miRNAs in other species reported in miRBase v21 and precursor genome coordinates of the novel miRNAs were used to gain insight into their mechanism of biogenesis (Kim, 2005; O’Brien et al., 2018; Ruby et al., 2007).

For both 3'UTR-seq and sRNA-seq experiments, our biological replicates were well correlated (Pearson's correlation coefficient: 3'UTR-seq 0.95-0.97; sRNA-seq 0.86-0.90) (Supplementary figure S2A, S2B). Furthermore, gene expression level quantified by 3'UTRseq correlates well with microfluidic qPCR data previously generated from the same 55 RNA samples (178 puberty-related genes plus 5 control genes) (Hou et al., 2017) (median Spearman correlation coefficient: 0.74) (Figure 1C, Supplementary figure S1C). Using principal component analyses (PCA), we observed a separation of PD12 samples from PD22 and older for 
both gene and miRNA expression profiles along PC1 (Figure 1D, 1E). We also observed separation between male and female 3'UTR-seq samples along PC2 at all ages, which became more pronounced across postnatal age. In contrast, no obvious sex differences were observed in our miRNA expression data.

\section{Sex-biases in the transcriptome occur prior to puberty}

We quantified sex differences in the pituitary transcriptome by comparing the expression of genes and miRNAs between male and female samples at each age. Across all the profiled ages, we observed an increase in the numbers of sex-biased genes and miRNAs, with the most dramatic increase occurring at PD27, when all the males and half of the females had gone through puberty (Figure 1A, Figure 2A-B; see Table 1-2 for list of significant sex-biased genes and miRNAs; see Supplementary table S3-4 for full list of differential analysis results).

Although we observed most sex-biased gene expression at peri- and post-pubertal ages, sex differences in the pituitary begin to manifest earlier in postnatal development at PD12 (Table 1). At PD12, 12 genes, including seven sex chromosome linked genes: Ddx3y, Uty, Kdm5d, Gm29650, Eif2s3y (Y-linked), Xist and Kdm6a (X-linked); and five autosomal genes, Chrna4, Kcna4, Lhb, Th, and Drd4, are identified as significantly sex-biased (FDR $<0.05$, absolute fold change $>1.5$ ) (Figure 2C, Supplementary figure S3A). The seven sex chromosome-linked genes were consistently male- or female-biased across all the ages we profiled. Other than Ddx3y, Eif2s3y, Uty, Xist, and Lhb (Bjelobaba et al., 2015; Eckstrum et al., 2016), the other sexbiased genes we detected at PD12 have not been reported previously in pituitary.

We identified 25 male-biased (10 autosomal and 15 on Y chromosome) and 16 femalebiased genes ( 8 autosomal and 8 on X chromosome) at PD22 (Table 1), an age preceding 
puberty, including puberty-related genes $D g k k, F s h b, O s b p 2$, and $P c s k 1$, which we previously identified as being sex-biased using microfluidic qPCR (Hou et al., 2017) (Figure 2C,

Supplementary figure S3A). The 18 sex-biased autosomal genes at PD22 maintain the same sex-biased trend at all older ages we profiled, as shown by example genes Asb4 and Serpine2

(Figure 2A, 2C, Supplementary Figure S3A), demonstrating that there is establishment of sexbiased expression in the pituitary prior to puberty. Interestingly, 13 genes (Fshb, Pcskl, Serpine2, Lhb, Chrna4, Nupr1, Dgkk, Steap3, Timp1, Knca4, Gpr101, 2010007H06Rik, and Th) exhibited significant sex-biased changes between PD12 and PD22, which are ages preceding physical markers of puberty (tested for age and sex interaction effect, FDR $<0.05$ ), and all showed decreased expression in females and increased expression in males (Supplementary figure S3A). Several of these genes are associated with gonadotrope function: $F s h b$ and $L h b$ are genes encoding for gonadotrope-secreted hormones, Chrna4 is a marker for gonadotropes in rats (Fletcher et al., 2019), and Nuprl is known to be involved in embryonic gonadotrope development (Million Passe et al., 2008). While Nuprl mRNA was previously undetected in adults (Quirk et al., 2003), our results suggest its potential role in the early postnatal pituitary. Gpr101 and Serpine2 are known to be sex-biased in gonadotropes isolated from juvenile mice but not adult mice (Qiao et al., 2016). The functions of the remaining genes have not yet been described in gonadotropes or in the pituitary gland.

Next, we identified miRNAs which exhibited sex-biased expression prior to puberty: we found 1 and 2 sex-biased miRNAs at PD12 and PD22 respectively. The sex-biased miRNA at PD12 displayed female-biased expression and was previously identified in mice based on miRBase v21, and so we have tentatively named it here as novel46 (Figure 2E, Table 2, Supplementary figure S3B). Mature miRNA sequence alignment of novel46 to known mature 
miRNA sequences in other species found in miRBase v21 also revealed no known homologs. Based on its miRNA precursor coordinates, novel46 is a mirtron (a miRNA which is spliced from a host gene intron) expressed from the last intron of calcium voltage-gated channel subunit alpha1 G (Cacnalg), located on chromosome 11 (Supplementary table S2, Supplementary figure S3C). Cacnalg transcribes a component of T-type $\mathrm{Ca} 2+$ channel $\mathrm{Ca}_{\mathrm{v}} 3.1$, which has been shown in anterior pituitary primary cells to promote LH secretion by estradiol signaling through estrogen receptor 1 (ESR1) upon GnRH-induction (Kim et al., 2011). We found that Cacnalg exhibits female-biased expression at PD32 and PD37 (Supplementary figure S3D). Discordant expression profile of novel46 and Cacnalg suggests that novel46 could be transcribed from an independent promoter or regulated by crosstalk between the spliceosome and the microprocessor complex (possible mechanisms are reviewed in (Liu et al., 2018)).

At PD22, we found that miR-499-5p displayed male-biased expression, whereas miR342-5p displayed female-biased expression (Figure 2E, Table 2, Supplementary figure S3B). Based on their miRNA precursor coordinates, miR-499-5p and miR-342-5p were also found to be mirtrons: they are expressed from $M y h 7 b$ and $E v l$ respectively. Neither $M y h 7 b$ nor $E v l$ were detected as significantly sex-biased at any profiled age. The functions of both the miRNAs and their host genes have not yet been described in the pituitary gland.

\section{Peri- and post-pubertal sex differences in gene expression reflect sex differences in pituitary endocrine functions}

At peri- and post-pubertal stages we detected similar numbers of male- and female-biased genes. The number of sex-biased genes roughly doubled across the pubertal transition (140, 253, and 351 male-biased genes and 156, 232, and 294 female-biased genes at PD27, PD32, and 
PD37, respectively; Figure 2A, Table 1, Supplementary table S3). Many of these genes (43 male and 73 female-biased) showed sex biased gene expression throughout the pubertal transition (Figure 2D, Supplementary figure S3A). While we recovered genes with previously known sex-biased expression in pituitary, such as Dlkl and $\operatorname{Prl}$ (Bjelobaba et al., 2015; Cheung et al., 2013; Hou et al., 2017), many other sex-biased genes that are highly expressed, including Nnat, which is among the most abundant transcripts in the pituitary (Nishida et al., 2005b), were found and warrant further investigation. Male-biased genes are enriched for pathways related to hormone synthesis and secretion (Figure 2F, 2G, Supplementary table S5), including "peptide hormone biosynthesis" (PD27, $\mathrm{p}=7.22 \mathrm{e}-06)$, "regulation of secretion" $(\mathrm{PD} 37, \mathrm{p}=7.87 \mathrm{e}-03)$, and "secretory vesicle" $(\mathrm{PD} 37, \mathrm{p}=4.9 \mathrm{e}-04)$; and pathways related to reproduction, including "male sex differentiation" $(\mathrm{PD} 37, \mathrm{p}=4.76 \mathrm{e}-02)$ and "reproductive process" $(\mathrm{PD} 27, \mathrm{p}=4.14 \mathrm{e}-$ 02). In addition, male-biased genes are enriched for pathways associated with signaling receptors, ion channels, extracellular region, and plasma membrane, like "G-protein coupled receptor signaling pathway", which is enriched at all three ages (PD27: $\mathrm{p}=4.7 \mathrm{e}-02 ; \mathrm{PD} 32: \mathrm{p}=$ 1.22e-03; PD37: $\mathrm{p}=8.67 \mathrm{e}-03$ ). These pathways highlight sex-biases in components important for cell signaling, particularly in pituitary endocrine cells which are known to be activated in a neuron-like manner, such as through ion channels and G-protein coupled receptors (Stojilkovic et al., 2017, 2010). Finally, pathways related to endopeptidase inhibitor activity are also enriched, including several serpine family genes (Serpine2, Serpina3c, and Serpinb1a). It is possible that these endopeptidase inhibitors are involved in sex-biased processing of peptide hormones or neuropeptides.

Female-biased genes, including Stat5a, Cckbr, Slit2, Robo2, Nrip1, Nhlh2, Prl, and Pgr, are enriched for "ovulation cycle" (PD37: $\mathrm{p}=1.03 \mathrm{e}-02)$, linking female-biased pituitary genes to 
female-specific physiological processes. Notably, other female-biased pathways are predominantly neuron-related (Figure 2G, Supplementary table S5), which could be attributed to genes expressed in the posterior pituitary, which contains axons extended from the hypothalamus, or genes expressed in neuroendocrine cells (Robinson and Verbalis, 2011). Particularly, female-biased genes at all three ages, including Crhbp, Prl, Calb1, Pgr, Pak7, Reln, Dmrta1, Prkce, Ar, Nhlh2, Grm5, and Cacnalc, are enriched for "behavior" (PD27: p = 5.32e03; PD32: $\mathrm{p}=4.25 \mathrm{e}-02$; PD37: $\mathrm{p}=5.32 \mathrm{e}-03$ ). Several of these genes, Crhbp, Calb1 (J.-T. Li et al., 2017), Prkce (Hodge et al., 2002), Cacnalc (Moon et al., 2018), and Grm5 (Shin et al., 2015) are related to the regulation of stress, which is sex-biased in its activity (Oyola and Handa, 2017). Crhbp encodes corticotropin-releasing hormone binding protein (CRH-BP), whose mRNA and protein levels are both higher in female mouse pituitary (Speert et al., 2002). CRHBP inhibits ACTH secretion by binding to $\mathrm{CRH}$ and its expression is induced by stress resulting in a stronger attenuation of stress response in females (Stinnett et al., 2015). However, other than Crhbp, the sex-biased expression and the functions of these genes have not been studied in the pituitary.

For miRNAs, we detected 3 and 4 male-biased miRNAs and 3 and 8 female-biased miRNAs at PD27 and PD32 respectively (Figure 2B, Table 2, Supplementary figure S3B, Supplementary table S4). miR-224-5p, a mirtron of Gabre, and miR-383-5p, a mirtron of $S g c z$, respectively displayed male- and female-biased expression levels that are consistently detected from PD27 to PD32 (Figure 2E, Table 2). miR-224-5p has been reported to promote ovarian granulosa cell (GC) proliferation with TGF $\beta 1$ stimulation (Yao et al., 2010). Meanwhile miR383-5p was also shown to respond to TGF $\beta 1$ stimulation but inhibit GC proliferation (Wei and Gao, 2019; Yin et al., 2012). Given that TGF $\beta 1$ signaling is also a known inhibitor of lactotrope 
proliferation (Sarkar et al., 2005), it would be interesting to know if miR-224-5p and miR-383-

$5 \mathrm{p}$ have a role in TGF $\beta 1$-mediated lactotrope proliferation.

\section{Linking sex-biased genes to pituitary disease, pituitary development, and pubertal onset}

To further assess the role of our identified sex-biased genes in pituitary pathophysiology, we compiled a gene list consisting of (1) a list of "pituitary disease" genes implicated in combined pituitary hormone deficiency (CPHD) (Fang et al., 2016), pituitary adenoma (Hauser et al., 2019; Z. Ye et al., 2015), and neonatal hypopituitarism (Kurtoğlu et al., 2019); (2) a list of "puberty disease" genes implicated in the absence of puberty (idiopathic hypogonadotropic hypogonadism (IHH) and Kallmann syndrome) (Topaloğlu, 2017); (3) and a list of candidate "genes associated with pubertal timing by GWAS" for age at menarche in females (Day et al., 2017; Perry et al., 2014) and voice breaking in males (Day et al., 2015; Hollis et al., 2020). We found that sex-biased genes were enriched for genes in this combined list (hypergeometric test, $p$ $=2.67 \mathrm{e}-5$, fold enrichment $=1.8)$. These disease and complex trait-associated genes are highlighted in Table 1. Notably, "pituitary disease" genes Gh, Igsfl, and Pcsk1 are sex-biased at multiple ages. Pcsk1 encodes prohormone convertase 1/3 (PC1/3) and is crucial for processing several neuropeptides and peptide hormones including pro-opiomelanocortin (POMC) (reviewed by (Stijnen et al., 2016). Igsfl encodes for immunoglobulin superfamily member 1 and has been implicated in combined pituitary hormone deficiency: patients with mutations in Igsfl can present with central hypothyroidism, GH/PRL deficiencies, and abnormal enlargement of the testes (macroorchidismd) (Fang et al., 2016; Hughes et al., 2016; Joustra et al., 2013). 


\section{Connecting sex-biased miRNAs to target genes with sex-biased expression}

To evaluate post-transcriptional regulation of sex-biased changes in the pituitary gland by miRNAs, we identified computationally predicted or experimentally validated miRNA-target gene pairs that both exhibit sex-biased expression. Since miRNAs are usually predicted to repress target gene expression, we additionally required miRNA and target gene pairs to be significantly negatively correlated in expression across matched samples (Spearman's rho $<0$, FDR < 0.1) (see Materials and Methods for details) (Figure 3A, Supplementary table S6).

At pre-pubertal ages, PD12 and PD22, we did not identify any negatively correlated miRNA-gene pairs where the miRNA and its target gene were sex-biased. This is likely due to the relatively lower number of sex-biased genes and miRNAs identified at these pre-pubertal ages compared to post-pubertal ages.

At peri- and post-pubertal ages, we found that the male-biased miRNAs miR-181a-5p (at PD27) and miR-224-5p (at PD27 and PD32) showed significant negative correlation with female-biased target genes, Ammecrl (target of miR-181a-5p and miR-224-5p), Ankl (target of miR-181a-5p), and Prkce (target of miR-181a-5p) (Figure 3A, Supplementary table S6). All three of these target genes have been shown to be estradiol-responsive (Dina et al., 2001; Kim et al., 2011) and are female-biased from PD27 onwards, suggesting a role for miR-181a-5p and miR-224-5p in regulating the pituitary response to increased circulating estradiol levels at puberty. Both Ammecrl and Ankl were previously identified as a target of miR-181a-5p in P13 mouse brain by Ago HITS-CLIP (Chi et al., 2009) and Ammecrl was previously identified as a target of miR-181a-5p in HeLA cells by microarray (Grimson et al., 2007). In comparison, female-biased miR-205-5p (at PD32) was negatively correlated with Inhba (Figure 3A, Supplementary table S6). Inhba is a male-biased puberty-associated gene (Day et al., 2017; 
Perry et al., 2014) encoding for a subunit of inhibin, which is an inhibitor of FSH production in gonadotropes (Ling et al., 1986). Therefore, negative correlation of miR-205-5p to Inhba suggests that miR-205-5p may be relevant to sex biases to inhibin-regulated secretion of FSH from the pituitary gland.

\section{Predicting transcriptional regulators associated with sex-biased pituitary gene expression}

Sex-biased expression of transcription factors (TFs) represents a powerful mechanism by which to drive sex-biased regulatory networks. Of the sex-biased genes we detected, five malebiased and 16 female-biased genes are annotated as TFs in mouse by AnimalTFDB3 (Hu et al., 2019) (Figure 3B). Known molecular functions in the pituitary and pituitary-related knockout phenotypes of these 21 sex-biased TFs are summarized in Table 3. Importantly, male-biased gene Cebpd has been shown to inhibit PRL expression and lactotrope proliferation (Tong et al., 2011). In addition, Gata2 and Neurod4 are required for pituitary development (Charles et al., 2006; Zhu et al., 2006) and knockout of $A r$ or Nhlh2 results in pituitary phenotypes including decreased preovulatory surge levels of LH and FSH (Wu et al., 2014) and hypoplastic pituitary (Cogliati et al., 2007).

To gain insights into how TFs might regulate sex-biased pituitary gene expression across pubertal transition, we focused on the genes we classified as having biased gene expression at two or more postnatal days in males $(n=183)$ or females $(n=174)$. We used epigenetic Landscape In Silico deletion Analysis (Lisa) tool (Qin et al., 2020), which builds transcriptional regulatory models based on both publicly available DNase and ChIP-seq datasets and imputed transcriptional regulator (TR) binding sites to predict TRs that regulate a group of query genes. We identified 6 and 22 TFs $(\Delta-\log 10(P$-value $)>$ mean \pm 2 SD $)$ including gonadal nuclear 
hormone receptors, ESR1 and AR, that were predicted to regulate female-biased and male-biased genes respectively. In addition, CBX7, a component of Polycomb repressive complex 1 (PRC1), as well as SUZ12 and EZH2, components of Polycomb repressive complex 2 (PRC2), were predicted by Lisa to regulate female-biased genes. In contrast, a heterodimeric TF, CLOCK:BMAL1 (ARNTL), was predicted by Lisa to regulate male-biased gene expression (Figure 3C).

\section{Gene co-expression analysis reveals dynamic modules corresponding to pituitary cell types}

To further characterize dynamic changes in the pituitary transcriptome we utilized our temporal and sex-dependent gene expression profiling of the postnatal pituitary to build gene coexpression networks. Co-expressing genes tend to share related functions or regulatory pathways, and hence these networks are an effective approach to systemically explore mechanisms underlying sex-biased postnatal pituitary development. We used CEMiTool (Russo et al., 2018) to identify transcriptome-wide gene expression correlation networks in the postnatal pituitary transcriptome. Briefly, CEMiTool selects genes with high variation in expression and then groups filtered genes based on their similarity in expression across multiple conditions into co-expressing gene modules (see Materials and Methods for details). In total, nine coexpression gene modules were identified based on the expression of 1205 genes (Figure 4,

\section{Supplementary figure S4, S5, Supplementary table S7).}

The temporal expression profiles of the 9 co-expression gene modules can be defined by three general patterns: 1) decreasing expression, particularly between PD12 and PD22 (Modules 1 (M1, M4, M7, and M8); 2) increasing expression (M2 and M3); and 3) sex-biased expression (M5, M6, and M9) (Figure 4, Supplementary figure S5A, S5B). To further understand the 
nature of the co-expression modules, we used three methods: 1) pathway enrichment analysis using module genes, 2) identification of hub genes, and 3) examination of module gene expression in pituitary scRNA-seq data. We found that these modules largely capture cell-typeenriched gene expression signatures. For example, M7, which shows decreased expression, is enriched for cell cycle-related pathways (Supplementary figure S5C). In addition, the top hub genes (genes with highest within module connectivities defined by CEMiTool) of M7 (Top2a, Mki67, Cdca3, Cenpf, and Prc1), are all essential for cell mitosis and are markers of proliferating cells. Finally, taking advantage of a published single-cell transcriptome of adult male mouse pituitary gland (Cheung et al., 2018) (Figure 5A, Supplementary figure S6), we found that M7 genes are enriched within the proliferating $($ Poulfl+) cell population. Collectively, we conclude that module M7 represents genes that are enriched in proliferating cells.

Similar trends are observed for other modules. The top hub genes of M2 and M5 include Gh and Dlk1 (Figure 4), markers of somatotropes (Cheung et al., 2013), and M2 and M5 genes showed enrichment for somatotrope clusters (Figure 5B). Similarly, the top hub gene of M3 is Prl, a marker of lactotropes, and M3 genes showed enrichment for the lactotrope clusters. Top hub genes of M9 include Fshb and Rab3b, both of which are required for GnRH-induced gonadotropin release (Tasaka et al., 1998), and we found M9 genes to have enrichment for the gonadotrope cluster. Finally, the top 10 hub genes in M8 consist of pituicyte markers, including Col13a1, Scn7, and Col25al (Chen et al., 2020) show enrichment within the pituicytes (posterior) cell cluster. The top hub genes in M8 likely reflect the important role of pituicytes in promoting proper vascular development in the postnatal posterior pituitary by extracellular matrix-related pathways (Anbalagan et al., 2018) (Figure 4). Overall, we observe a clear 
association between cell types and specific gene co-expression modules identified in the pituitary gland.

\section{Sex differences in cell proportions emerge prior to puberty}

Although sex differences in cellular composition of the adult pituitary gland have been well-established (Ho et al., 2020; Sasaki and Iwama, 1988), much less is known about when sex differences in pituitary gland cell composition arise during postnatal development. To assess cell proportion changes in each sex during postnatal development, we estimated cell proportions in our postnatal time-series bulk profiling using CIBERSORT (Newman et al., 2015), a single-cell deconvolution method, with the reprocessed single-cell adult male pituitary transcriptome (Cheung et al., 2018) (Figure 5C, Supplementary figure S7).

We found cell proportions of stem cells (Sox2+) decreasing from PD22 onwards in parallel with cell proportions of major hormone-producing cell populations increasing, such as somatotropes, lactotropes, and gonadotropes (Figure 5C). This observation likely reflects the active establishment of pituitary hormone-producing cell populations from Sox $2+$ cells in the developing postnatal pituitary (Andoniadou et al., 2013; Rizzoti et al., 2013). We report that proliferating cells begin to decrease in cell proportions around PD12 and PD22, a phenomenon previously shown in the rat anterior pituitary and mouse pituitary (Oishi et al., 1993; Zhu et al., 2015). Between PD12 and PD22, ages prior to puberty, we found that sex differences in gonadotrope cell proportions begin to emerge (Figure 5C). At PD27, when puberty has occurred in a subset of our mice (Figure 1A), we observed the emergence of male bias in somatotrope cell proportions and female bias in lactotrope cell proportions (Figure 5C). The emergence of sex differences in relative cell proportions at ages leading up to and including puberty suggest that 
pubertal transition may be a key time window for the establishment of sex-biased proportions of hormone-producing cells observed in adult mice (Ho et al., 2020; Ruf-Zamojski et al., 2021; Sasaki and Iwama, 1988).

\section{Inferring cell-type-specific sex-biased genes}

We next wanted to examine if any sex-biased genes identified remained sex-biased after adjusting for cell-type proportion differences. To do this, we used a bioinformatic pipeline, Single-cell mapper (scMappR) (Sokolowski et al., 2021) to calculate a cell-weighted fold-change for each sex-biased gene identified in our bulk RNA-seq data. Cell-weighted fold-changes (cwFC) were calculated for each gene by readjusting the bulk gene expression fold change with the cell-type specificity of the gene and the ratio of deconvolution-estimated cell type proportions (determined by scRNA-seq). We considered genes with with an absolute cwFC $>0.5$ to be cell-type-specific sex-biased genes and identified 67 cell-type-specific, sex-biased genes, all of which were found to be sex-biased at PD37 (Figure 5D, Supplementary table S8). Of these cell-type-specific sex-biased genes, 6 genes (Fshb, Gata2, Appl2, Ddx3y, Rab3b, Ecell) were found to be concordantly sex-biased in the corresponding cell-type in the rat anterior pituitary (genes highlighted in Figure 5D, Supplementary table S9 (Fletcher et al., 2019)).

Several of these genes have plausible links to regulating sex-biases in the pituitary gland. For example, the male-biased expression of $R a b 3 b$ is consistent with its inhibitory role of PRL secretion in males (Perez et al., 1994) and the male-biased expression of Gata2 in gonadotropes is consistent with growth deficiency observed with pituitary-specific Gata2 KO mice (Charles et al., 2006) and the male-specific reduction in serum FSH in gonadotrope-specific Gata2 KO mice (Schang, 2020). Our predicted male-biased expression of Rxrg in somatotropes may be 
relevant to the RAR-RXR receptor complexes role mediating growth hormone release in anterior pituitary cells (Maliza et al., 2016). Several genes we identified by scMappR as being cell-typespecific and sex-biased were previously associated with: pubertal onset phenotypes discovered by age-at-menarche GWAS (Fshb, Dgkk, Rxrg, Cadps2, Dlk1, Igsf1, Sytl4, Dlgapl) (Day et al., 2017; Perry et al., 2014); and voice-breaking GWAS in males (Dlgapl and Igsf1) (Day et al., 2015). In addition genes with cell-type-specific and sex-biased expression involved or likely involved in disorders of puberty/reproductive system include Fshb (Matthews et al., 1993), Dlk1 (Dauber et al., 2017), Igsfl (Joustra et al., 2015), and Dgkk (van der Zanden et al., 2011) (genes highlighted in Figure 5D, Supplementary table S9). Thus, by combining our temporal postnatal bulk pituitary 3'UTR-seq with single-cell RNA-seq datasets we can infer pituitary cell type specificity of sex-biased genes.

\section{Discussion}

The pituitary gland displays sex differences in its regulated physiological functions, including stress response, somatic growth, reproduction, and pubertal timing. By comparing pituitary gland mRNA and miRNA expression profiles between male and female mice during postnatal development, we identified sex-biased mRNA and miRNAs that are likely to be part of active gene regulatory networks active across pubertal maturation and that may underlie some sex differences in pituitary function.

Notably, we observed sex-biased expression of genes and miRNAs prior to onset of physical markers of puberty (VO/PS) at PD12 and PD22, suggesting these sex differences may be independent of effects from changes in gonadal hormone levels at puberty. These sex differences may be attributed to irreversible organizational effects (McCarthy and Arnold, 2011) 
that are established by gonadal hormone exposures during fetal development and perhaps in the first week after birth in mice (R. Li et al., 2017). Unlike activational effects, sex differences established by organizational effects persist even when gonadal hormones are no longer present in the system, such as at pre-pubertal ages. We found that many sex-biased genes identified between PD12-PD22 are expressed in the gonadotropes, including $F$ shb and $L h b$. We also predicted by single-cell deconvolution that gonadotrope cell proportions are male-biased prior to puberty. As gonadotropes produce LH and FSH to regulate gonadal maturation during puberty, these pre-pubertal sex differences in gonadotrope cell proportions and sex-biased expression suggest that these sex differences are necessary to prime the pituitary gland for its regulation of gonadal maturation during puberty. It is interesting to speculate about whether any of the differences we have observed could also underlie differences in the timing of puberty between males and females.

We also showed that most of the sex-biased gene expression occurs upon the onset of puberty and remains male- or female-biased. Using Lisa (Qin et al., 2020), we predicted that estrogen and androgen receptors (ESR1 and AR) are likely involved in regulating female- and male-biased gene expression, suggesting an ongoing pituitary response to pubertal gonadal hormone levels. We also predicted components of Polycomb repressive complex (PRC) 1 and 2 in regulating female-biased genes. Interestingly, female-biased genes identified in multiple human tissues by GTEx, including the pituitary gland, were previously reported to be enriched for Polycomb epigenetic silencing (Oliva et al., 2020). In addition, the sex-biased deposition of H3K27me3 marks by EZH1/EZH2 complex has been shown to repress female-biased expression in the male adult mouse liver (Lau-Corona et al., 2020). Furthermore, PRC is also involved in the 
regulation of pubertal onset in female rats by inhibiting Kiss 1 expression in the arcuate nucleus to prevent the premature initiation of puberty (Lomniczi et al., 2013).

However, these transcriptional regulators were predicted using datasets generated in other cellular environments, and hence future experiments in both sexes of the mouse pituitary, such as ATAC-seq and ChIP-seq, would be of interest to further identify sex differences in chromatin accessibility and TF binding. Recently, Ruf-Zamojski et al. performed scRNA-seq and scATACseq in male and female adult mice (10-12 weeks) (Ruf-Zamojski et al., 2021). While the authors discussed limited examples of sex-biased regulons, their dataset serves as a valuable resource to study the cis-regulation of sex-biased gene expression in a cell-type-specific manner and a model for future single-cell studies aiming at further dissecting sex-biased gene regulatory networks. Although the number of sex-biased miRNAs are small $(n=17)$, it is important to consider that a single miRNA has the potential to target and regulate multiple genes and their protein products (Lim et al., 2005; Selbach et al., 2008). miRNAs likely have important roles in responding to sex-biased hormonal release across multiple hypothalamic-pituitary axes. Specifically, multiple miRNAs have been shown to be estrogen-responsive in the neonatal mouse hypothalamus by the administration of an aromatase inhibitor (Morgan and Bale, 2017). miR-1948 and miR-802, identified as sex-biased in adult mouse liver, are known to be regulated by sex-biased pattern of growth hormone release from the pituitary gland (Hao and Waxman, 2018). Here we also identified two male-biased miRNAs, miR-181-5p and miR-224-5p, that may regulate the pituitary response to increasing gonadal hormone levels at puberty, as their target genes (Ammecr, Ankl, Prkce) have previously been shown to be estradiol-responsive (Dina et al., 2001; Kim et al., 2011). However, the miRNA-gene targets that we identified in this study are based on experimental validations performed in other tissues and/or computational 
predictions; therefore, further validation by luciferase reporter assays and Ago2 HITS-CLIP in the pituitary would be valuable.

Sex differences in cell-type composition of the pituitary gland have been known for more than two decades (Sasaki and Iwama, 1988). In addition, in response to physiological demands, the pituitary cell composition exhibits dynamic changes, such as lactation and pregnancy, where there is an increase in lactotropes (Ho et al., 2020; Scheithauer et al., 1990). There are several proposed mechanisms by which cell composition changes arise in the pituitary gland: differentiation from the adult pituitary stem cell niche (Andoniadou et al., 2013), transdifferentiation from differentiated cell-types (Ho et al., 2020; Scheithauer et al., 1990), and self-proliferation from existing cell-types (Oishi et al., 1993; Taniguchi et al., 2002). Leveraging our bulk RNA-seq data with multiple biological replicates across multiple postnatal ages combined with available single-cell data (Cheung et al., 2018), we predicted a decrease in progenitor cell proportions in parallel with an increase in the proportions of somatotropes, lactotropes, and gonadotropes, suggesting differentiation from the adult stem cell niche may be occurring around PD22. In addition, we may also be observing transdifferentiation from melanotropes and corticotropes, which are decreasing in cell proportions, toward somatotropes, lactotropes, and gonadotropes which are increasing in proportions and are increasingly sexbiased at the later ages we studied. However, the extrinsic and intrinsic signals driving these sexbiased changes in pituitary cell-type proportions are not well understood.

Using scMappR, we were able to control for cell-type proportion sex differences and infer genes that still maintained sex-biased gene expression, including sex-biased genes which were previously identified in the adult rat anterior pituitary (Fshb, Ecell, Rab3b, and Gata2). 
However, our scMappR analysis did not capture gene expression changes that are purely driven by cell-type proportion differences and is limited to genes which display cell-type specificity. Another limitation of single-cell deconvolution analysis is that it can only provide an estimation of cell proportions in bulk data and are dependent on how well matched both datasets are in terms of biological variables such as age and sex. While currently cost-prohibitive, our results suggest that a similar experimental design in the future with single-cell technologies (multiple replicates of male and female mice at multiple postnatal timepoints) will provide more specific insight into the mechanisms underlying sex-biased gene expression and the molecular mechanisms that give rise to cell-type proportion differences during postnatal development in the pituitary. Support for this approach is seen in the aforementioned recent work which used scRNA-seq and scATAC-seq to characterize the sex-biased specific regulatory landscape of the mouse pituitary (Ruf-Zamojski et al., 2021). In this study, the authors highlighted a group of genes with female-biased expression using latent variable analysis. We found that 10 of the top 30 genes highlighted (Ankra2, Crhbp, Ddx21, Ern1, Gadd45g, Greb1, Npr2, Nrg4, Rps6ka2, Stat5a) show female-biased expression in one or more postnatal ages in our dataset too.

In comparison, our knowledge of miRNA cell-type specificity is limited based on their detection in pituitary single-cell studies. However, inferences may be made based on the expression of host genes for mirtrons. For example, $\mathrm{Sgcz}$, the host gene of female-biased miR383-5p, displays specific expression in a putative lactosomatotrope population (Ruf-Zamojski et al., 2021), suggesting miR-383-5p may also be expressed from a similar population of cells. Future experiments that directly identify cell-types in which sex-biased miRNAs (canonical and mirtrons) are expressed in would be valuable to further explore the mechanisms of sex-biased 
miRNA regulation and assess the effect of cell-type proportion differences on bulk sex-biased miRNA expression.

By profiling of pituitary mRNA and miRNA expression across the pubertal transition, we highlight the dynamic nature of gene regulation and cell type composition differences in males and females. While the biological importance of some of these sex differences are established, many of these (especially the miRNAs), as well as the mechanisms that give rise to early prepubertal sex differences in cell type composition, remain unknown. Given the central importance and conservation of the physiological processes regulated by the pituitary gland, further study of these sex differences in animal models will inform our understanding of human health and disease.

\section{Methods}

\section{Animal and tissue collection}

All studies and procedures were approved by the Toronto Centre for Phenogenomics (TCP) Animal Care Committee (AUP 09-08-0097) in accordance with recommendations of the Canadian Council on Animal Care, the requirements under Animals for Research Act, RSO 1980, and the TCP Committee Policies and Guidelines. Conditions in which mice were maintained, sacrificed, and dissected are described previously in (Hou et al., 2017). Upon dissection, the pituitary gland was directly moved to RNAlater (containing 10\% w/v sodium citrate tribasic dihydrate and $60 \% \mathrm{w} / \mathrm{v}$ ammonium sulphate) following dissection and stored at $20^{\circ} \mathrm{C}$ until RNA extraction. 


\section{RNA extraction}

Prior to RNA extraction, pituitary tissue samples were placed into bead mill tubes containing six 1.4-mm ceramic beads (MoBio Laboratories) and homogenized for $30 \mathrm{~s}$ at $6.5 \mathrm{~m} / \mathrm{s}$ at $4{ }^{\circ} \mathrm{C}$ using an Omni Bead Ruptor 24 bead mill. RNA was extracted with the NucleoSpin ${ }^{\circledR}$ miRNA kit (Macherey Nagel) in combination with TRIzol lysis (Invitrogen) following the manufacturers' protocols, allowing for collection of small RNA $(<200 \mathrm{nt})$ and large RNA $(>200$ nt) simultaneously into separate tubes from total RNA. RNA quantity was determined using Nanodrop and the quality was assessed by an Agilent 2100 Bioanalyzer.

\section{Library preparation and sequencing}

To construct RNA-seq libraries, we established an automated 3'UTR-seq (QuantSeq 3'mRNA-seq; Lexogen GmbH, Vienna) using the Agilent NGS Workstation (Agilent Technologies, Santa Clara) at The Centre for Applied Genomics (TCAG) (Toronto, Canada) as per the manufacturer's protocol (Yuki et al., 2018). Briefly, $250 \mathrm{ng}$ of RNA, from the large RNA fraction, was used to generate cDNA. cDNA was amplified with 17 PCR cycles as determined by qPCR analysis using the PCR Add-on kit (Lexogen). ERCC RNA spike-in Mix 1 was added following the manufacturer's instructions. The resulting libraries were quantified with Qubit DNA HS (Thermo Fisher, Waltham) and fragment sizes analyzed on the Agilent Bioanalyzer using the High Sensitivity DNA assay prior to sequencing. Sequencing was performed at TCAG on the HiSeq 2500 v4 flow cell (Illumina, San Diego) with SR50 bp with cycles extended to 68bp. Small RNA-seq libraries were constructed from the small RNA fraction by TCAG using NEBNext Small RNA Library Prep Kit (New England BioLabs) according to the manufacturer's protocol. Sequencing was performed at TCAG on a HiSeq 2500 v4 flow cell with SR50 bp. 


\section{mRNA sequencing reads processing}

FastQC (http://www.bioinformatics.babraham.ac.uk/projects/fastqc/) was used to examine the quality of sequenced reads. Next, a customized script was used to trim both the polyAs and adaptors sequences at the end of the reads. A subset of sequencing reads obtained from 3'UTR-seq show a mixture of polyAs and sequencing adapters towards the end of the reads, which are not effectively trimmed by available read-trimming tools. We developed a trimming strategy which can identify and trim off polyA sequences embedded in the adapter sequences. Only reads longer than $36 \mathrm{bp}$ after trimming were used. In addition, the first 12 nucleotides were trimmed based on the manufacturer's recommendations. After trimming, FastQC was performed again to examine read quality. At this step, we found that ribosomal reads were overrepresented in the pituitary samples through priming by oligo(dT) binding to Arich regions in the ribosomal RNA loci. In addition, the sequence of a brain-enriched small RNA, $\mathrm{BC} 1$, is also represented. Thus, reads that map to these overrepresented transcripts were removed. Trimmed and filtered reads were aligned to the genome using a splice-aware aligner, STAR (version 2.5.1b) (Dobin et al., 2013), with default settings except “-outFilterMismatchNoverLmax 0.05 " for QuantSeq. Quality control of mapped RNA-seq reads was performed using Qualimap (version 2.2.1) (Okonechnikov et al., 2016).

\section{PolyA site identification and gene annotation modification}

GENCODE version M21 was the primary annotation used. To achieve a more comprehensive annotation of the 3'UTRs, we also incorporated the 3'UTRs annotated in RefSeq, which is obtained from the UCSC database (mm10). In addition, we also identified potential polyA (pA) sites from the data. To do this, only the 3 ' most nucleotide of each read is used to build a signal track for each sample. R package "derfinder" (Collado-Torres et al., 2017) was 
used to identify expressed regions (ER) from these signal tracks. Specifically, an average read pile-up cutoff of 1 RPM (reads per million mapped reads) was used. ERs are annotated to gene annotations (3'UTR, 5' UTR, exons, introns, and intergenic regions) based on GENCODE version M21, allowing for overlapping categories. ERs mapped to introns and intergenic regions are further analyzed to identify novel polyA sites. To filter for potential internal polyA priming events, sequence composition around ERs is examined. ERs with a) matches 18-mer polyAs (with up to 6 mismatches) within $150 \mathrm{bp}$ downstream from the ends; b) matches 7-mer polyAs (with up to 1 mismatches) within $20 \mathrm{bp}$ downstream from the ends; or c) more than $50 \%$ of the As within $20 \mathrm{bp}$ downstream from the ends, are removed. In addition, ERs that overlap more than $20 \mathrm{bp}$ with an annotated repeat region are also excluded. Filtered ERs are first mapped to RefSeq 3'UTR annotations (obtained from UCSC) and are associated with the corresponding genes. The rest of the unmapped ERs are then annotated to a) the corresponding gene if it is intronic, or b) the nearest gene upstream if it is within $5 \mathrm{~kb}$ from the gene ends. The intronic ERs are extended for $5 \mathrm{bp}$ in each direction and the ERs downstream of genes are used to extend the gene's 3'UTR annotation. The novel intronic polyA sites and extended gene annotations are then added to the gtf file used for gene counting. In total, additional internal polyA sites were added to 228 genes, and extended 3'UTRs were added to 476 genes, and 28 genes have both. Given the complexity of transcripts, the assignment to intronic polyA sites or 3'UTR extension may be impossible to distinguish in some cases. In addition, 2 of the 676 novel ERs did not make a difference to gene quantification as they overlapped with annotations from other genes.

\section{Gene quantification}

Trimmed and filtered reads were assigned to genes using featureCounts (v1.6.2) (Liao et al., 2014) with parameters “-s 1 -Q 255” for 3’UTR-seq. 


\section{Processing of small RNA-sequencing reads}

FastQC was used to examine the quality of sequenced reads. BBDuk (BBMap suite v37.90) was used to trim adapter sequences from reads with reference adapter sequences provided by BBMap suite and settings "hdist=1 mink=11" for small RNA-seq reads (Bushnell, 2014). For miRNA size specificity, only reads less than 23 nucleotides in length were retained. Following trimming, FastQC was used to examine the quality of trimmed sequenced reads. miRDeep2 mapper.pl was used with default parameters to map reads of at least 18 nucleotides in length to the mouse genome (mm10) (Friedländer et al., 2012). Known and novel miRNAs were identified using miRDeep2 main algorithm (miRDeep2.pl) with default parameters. For known miRNAs, the mature miRNA sequences in mouse were obtained from miRBase (v21) (Kozomara and Griffiths-Jones, 2014). For novel miRNAs, only those with miRDeep score $\geq 2$ and a sequence not matching previously reported small RNAs (rfam alert $=$ FALSE) were retained for downstream analysis.

\section{mRNA and miRNA normalization and differential analysis}

All of the following analyses were performed in R (v3.6.0) unless otherwise specified. Low-count mRNAs and miRNAs were filtered out prior to analysis. Only mRNAs and miRNAs with normalized read count (counts per million mapped reads, CPM) $>2$ in at least 10 samples were retained for downstream analysis. CPM was used because of the consistent read mapping with UTR-seq.

For mRNAs, mitochondrial genes were also removed and ERCC spike-ins were used to evaluate library quality but were not used for normalization. Remove Unwanted Variation from RNA-Seq Data (RUV-seq, v1.18.0) was used with RUVg() function with empirically detected 
negative genes to normalize and remove unwanted variations in mRNA data(Risso et al., 2014).

Empirical negative-control genes were identified with an ANOVA-like test comparing all conditions (FDR $<0.1)$. For miRNAs, RUV-seq was used with replicates (RUVs) to normalize and remove variation between batches from miRNA counts (Risso et al., 2014).

Quasi-likelihood F-test method was used to test for differential expression of mRNAs and miRNAs with a significance cutoff of absolute fold change $(\mathrm{FC})>1.5$ and false discovery rate corrected (FDR) < 0.05 using edgeR (v3.26.5) (McCarthy et al., 2012; Robinson et al., 2010).

\section{Novel miRNA identification}

The mature sequences of novel miRNAs which were included in the miRNA differential expression analysis were used for miRNA identification with "Single sequence search" function on miRBase (Kozomara et al., 2019) with the following parameters: "Search sequences: Mature miRNAs", "Search method: "BLASTN”, "E-value cutoff: 10”, "Maximum no. of hits: 100”, "Show results only from specific organisms: Mouse", "Word size: 4", "Match score: +5", "Mismatch penalty: -4 ". For miRNAs with more than one result, the miRNA with the best alignment (lowest E-value) is reported. If no miRNAs were identified in mouse, BLASTN was rerun with no species filter and the best alignment was reported. miRNAs with no results reported from any species are denoted with "NA".

\section{Predicting transcriptional regulation using Lisa}

Transcriptional regulator (TR) binding sites were predicted using Lisa (Qin et al., 2020) with genes which were female- or male-biased in 2 or more ages between PD27, PD32, PD37. The full Lisa model was applied ("TF ChIP-seq Peak-RP (regulatory potential)" and "ISD-RP (in silico deletion-regulatory potential) for both motif and ChIP-seq" methods) using the DNase-seq 
and H3K27Ac ChIP-seq data and 3000 genes which were randomly selected as the background gene set. Results combined from H3K27ac-ChIP-seq and DNase-seq ISD models, and TF ChIPseq peak-only models using the Cauchy combination test are shown for the ChIP-seq model.

\section{Pathway enrichment analysis}

All pathway enrichment analyses were performed using g:ProfileR (v0.6.7) in R. For differential expressed pathway enrichment, all detected genes in this dataset were used as background. For miRNA-gene target pathway enrichment, all gene targets detected in this dataset were used as background with parameters "min_set_size $=3$, min_isect_size $=2$ ".

\section{Co-expression module identification}

Gene co-expression modules were identified using CEMitool (Russo et al., 2018) (version 1.8.2) using log2-transformed, normalized read counts with default settings. Briefly, CEMitool first uses an unsupervised method to filter for genes with sufficient variation. By default, CEMitool models the variants of the genes as an inverse gamma distribution and chooses genes with a $\mathrm{p}$ value $<0.1$. Next, it automatically determines the similarity criteria before it separates genes into modules using the dynamic tree cut method. Hub genes are identified by ranking the summed similarities between a certain gene and all other genes in the same module.

\section{miRNA-gene target correlation}

Computationally predicted gene targets were curated from TargetScanMouse (v7.2)

(Agarwal et al., 2015) and experimentally validated gene targets were curated from miRTarBase (v8.0) (Chou et al., 2018). Only miRNA-gene target pairs from TargetScan with "Cumulative weight context score" $<-0.1$ were used. "Context score" for a specific target site is defined by Agarwal et al. 2015 as the summed contribution from 14 features which likely influence miRNA 
targeting a given gene, including "site type", "local AU”, “3' UTR length", and "Probability of conserved targeting" (full feature list

http://www.targetscan.org/vert 70/docs/context_score totals.html). Spearman's correlation coefficient (rho) was calculated for each pair using log2-transformed normalized counts and pvalues were adjusted with FDR to account for multiple testing. Pairs were considered negatively correlated if rho $<0$ and FDR-adjusted P-value $<0.1$.

\section{Cell-type enrichment analysis}

Single-cell transcript counts of adult male pituitary gland were reprocessed using Seurat 3.0 (Butler et al., 2018; Cheung et al., 2018). Cell types were identified using marker genes as identified previously (Chen et al., 2020; Cheung et al., 2018; Fletcher et al., 2019). KolmogorovSmirnov (KS) test was applied to compare the expression of a given module gene within each cell cluster versus all other cell clusters. Resulting p-values were FDR-corrected for multiple testing. Only module genes with FDR $p$-value $\leq 0.05$ in at least one cell cluster comparison were retained.

\section{Single-cell deconvolution}

CIBERSORT (https://cibersort.stanford.edu/) (Newman et al., 2015) was used to perform single-cell deconvolution. Reprocessed adult male pituitary gland single-cell transcriptome data (Cheung et al., 2018) with manually annotated cell types and raw counts from bulk pituitary gland from 3'UTR-seq (unwanted variation removed with RUV-seq) were used as inputs with parameters recommended for RNA-seq data ("permutations $=100$ ", "quantile normalization $=$ FALSE", "absolute mode = "FALSE").

\section{Identifying cell-type-specific sex-biased genes using scMappR}


Cell-weighted fold-change (cwFC) of PD37 sex-biased genes was calculated using scMappR (https://cran.r-project.org/package $=$ scMappR) with reprocessed adult male pituitary gland single-cell transcriptome (Cheung et al., 2018) in R v4.0.0. Genes with an absolute genenormalized $\mathrm{cwFC}>0.5$ for a given cell-type were considered cell-type-specific sex-biased genes.

\section{Data availability}

All 3'UTR-seq and small RNA-seq data from this study can be accessed through ArrayExpress accession numbers: E-MTAB-9459, E-MTAB-9460.

Author Contributions: Experimental and analysis study design was conceived by HH, C.Chan, DS, MFM, AG, ZZ, MRP, and MDW. Bioinformatic analysis was performed by HH, C.Chan and DS. Experiments were performed by KEY, AR, LUR, MH, C.Corre. Pipeline for preprocessing 3'UTR-seq data was developed by RQ and HH. The manuscript was written by HH, C.Chan, and MDW with support from all authors. AG, ZZ, MRP and MDW supervised and obtained funding for this work. All authors have read and approved the manuscript for publication.

Acknowledgements: We would like to thank: Theresa Ten Eyck (Agilent), Jekaterina Aleksejeva and Stephanie Bannister (Lexogen), Karen Ho and Sergio Pereira (The Centre for Applied Genomics (TCAG)) for their efforts and guidance setting up the automation of the QuantSeq protocol; and Sunyun Lee for assistance with setting up the Shiny app.

Funding: This work was supported by CIHR grants: 312557 (MRP/MDW/AG) and 437197 (Melissa Holmes/MDW/MRP). MDW is supported by the Canada Research Chairs Program. 
RQ, C.Chan and DS were supported in part by NSERC grant RGPIN-2019-07014 to MDW.

C.Chan and MH were supported by a SickKids RESTRACOMP scholarship. DS is supported by

NSERC CGS M, PGS D and Ontario Graduate Scholarships. HH is supported by the Genome

Canada Genomics Technology Platform, The Centre for Applied Genomics. MFM is supported

by NSERC PGS D and the association computing machinery special interest group on high

performance computing (ACM/SIGHPC) Intel Computational and Data Science Fellowship. LU

was supported by the CRS Scholarships for the Next Generation of Scientists. 


\section{Figures}

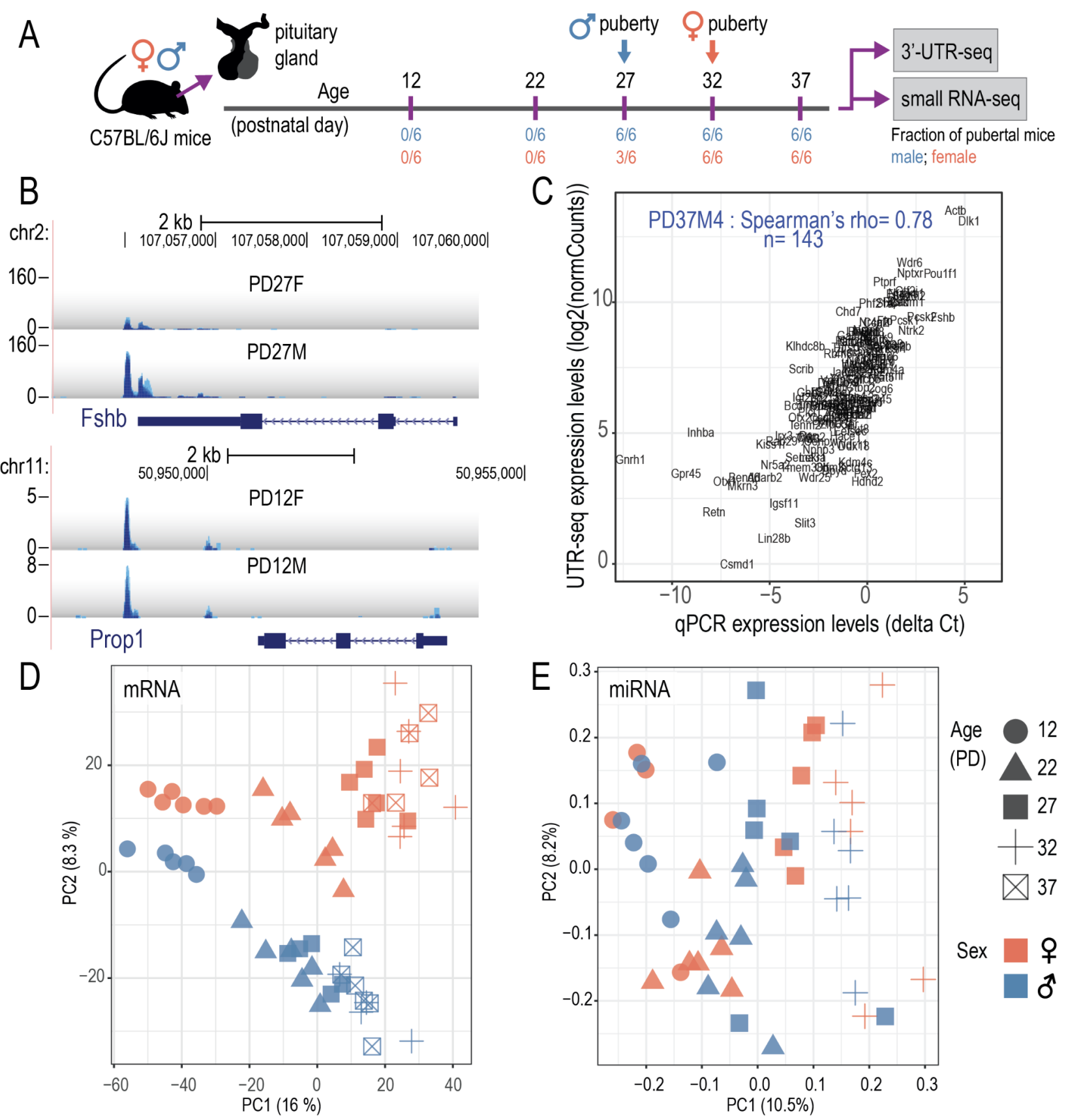

Figure 1. Overview of the pituitary transcriptome during postnatal development in male and female samples.

A. Schematic of experimental design. Marks (purple) on timeline denote age in which pituitary gland was collected. Vertical arrows denote average ages for onset of puberty of the specified sex in our colony (determined by preputial separation (males) or vaginal opening (females)). Fraction of pubertal mice out of total mice for males (blue) and females (red) at each age is shown. B. Genome browser screenshots showing QuantSeq signal at the Fshb and Prop1. $\mathrm{X}$-axis: genomic coordinates; y-axis: reads per million mapped reads (RPM); PD: postnatal day. 
Gene name and gene model are shown on the bottom of each panel. C. Scatter plot showing the correlation between gene quantification measured by qPCR and by 3'UTR-seq in one pituitary sample. $\mathrm{X}$-axis: $\Delta \mathrm{Ct}$ values obtained by $\mathrm{qPCR}$; y-axis: $\log 2$-transformed normalized counts ( $\log 2$ (normCounts)) values obtained by 3'UTR-seq. Sample names and Spearman correlation coefficients are labelled in each plot. PCA plot for pituitary gland samples based on (D) gene expression and (E) miRNA expression. PCA was performed using $\log 2$ (normCounts) after filtering for low-count genes and normalization using RUVseq. Only scores of the first 2 PCs are shown. Age is indicated by shape while sex is indicated by colors. 

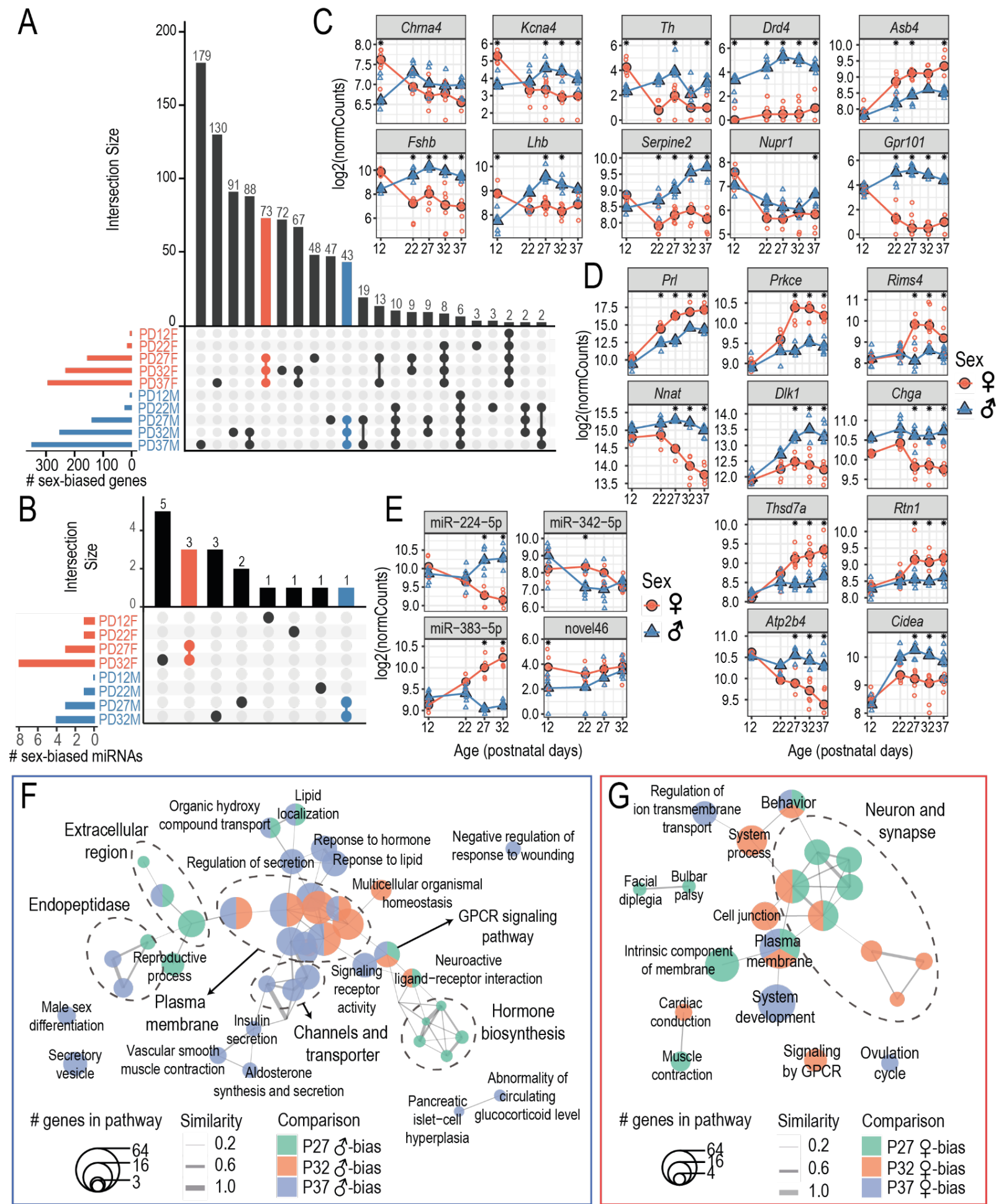

Figure 2. Pituitary transcriptome is increasingly sex-biased across postnatal development. Barplot showing the number of (A) intersecting sex-biased genes or (B) intersecting sexbiased miRNAs between each age. Horizontal bars on the left side show the numbers of male(blue) or female-biased (red) genes at each age. For example, "PD12F" represents genes which are found to be more highly expressed in females compared to males at PD12 (absolute FC > 1.5; 
FDR $<0.05)$. Different intersections are represented by the dotplot on the bottom, and their occurrence frequency is shown by the vertical barplots (top). Specifically, the coloured vertical bars represent the number of genes that are consistently female-biased (red) or male-biased (blue) at ages following pubertal onset (PD27, PD32, and PD37). Expression plots of example pre-pubertal (PD12-22) sex-biased genes (C) and peri-/post-pubertal sex-biased genes (D). Log2-transformed normalized counts ( $\log 2$ (normCounts)) are plotted for each gene. Expression changes are shown across ages (x-axis). Large, filled points represent median expression at each age and unfilled points represent each biological replicate. Blue: male samples; red: female samples. E. Expression plots of example sex-biased miRNAs. One example sex-biased miRNA is chosen for each given age. $\log 2$ (normCounts) are plotted for each miRNA across ages. Large, filled points represent median expression at each age and unfilled points represent each biological replicate. Red: female samples; blue: male samples. Network representation of pathways enriched for (F) male-biased and (G) female-biased differentially expressed genes. Each node represents a pathway and are connected based on similarity in genes found enriching for the connected pathways (Jaccard distance). Node size represents the number of differentially expressed genes enriching for the given pathway and nodes are coloured based on the differential expression comparison in which the genes were identified. Nodes are labeled based on similarity in pathway function. 


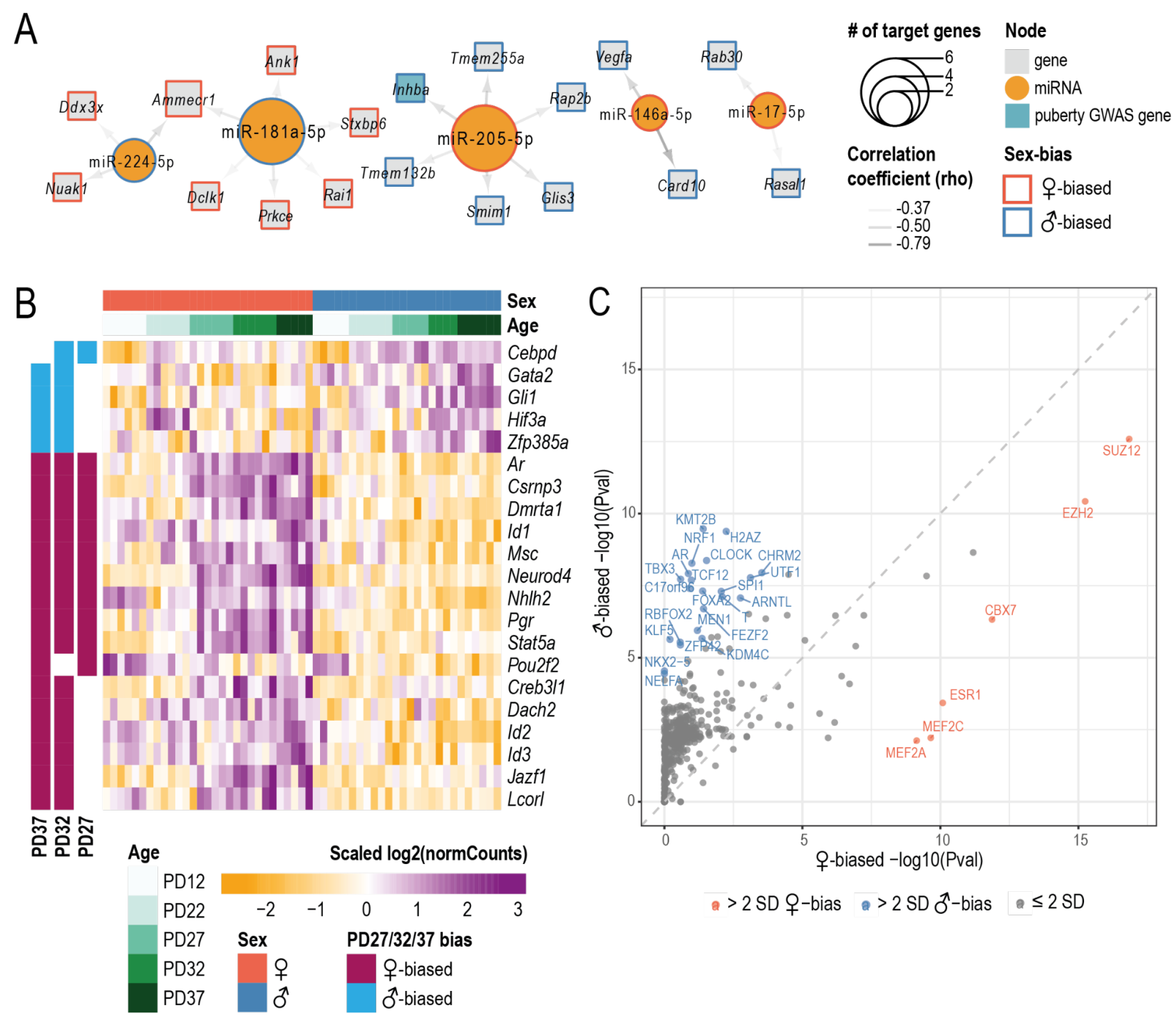

Figure 3. Regulation of sex-biased pituitary gene expression by miRNAs and transcription factors (TFs).
A. Interaction network of sex-biased miRNAs and their sex-biased target genes for all ages. Each node represents a gene (square) or a miRNA (orange circle) with the node size representing its number of connections with other nodes. Only miRNAs with number of connections $\geq 25 \%$ quantile based on the distribution of all connections $(n \geq 2)$. Edges between each node indicate a predicted interaction between the miRNA and gene with the edge thickness showing Spearman's correlation coefficient (rho) calculated for the given pair. Blue-filled nodes: genes identified as a puberty GWAS gene. Red outline on nodes indicate gene/miRNA is female-biased; blue outline on nodes indicate gene/miRNA is male-biased. B. Heatmap of sex-biased pituitary transcription factor (TF) gene expression. TFs which are consistently sex-biased in at least two ages between PD27, PD32, and PD37 are plotted. Colors of the heatmap represent row- scaled and centered expression levels of each gene. Column annotation bars indicate sample age and sex. Row annotation bars indicate age at which the gene was found to be sex-biased. $\mathbf{C}$. Scatterplot comparing Lisa TF rankings with combined P-values predicted to regulate 
female- and male-biased genes. Each TF is represented by a point and the combined $-\log 10(\mathrm{P}$ value) calculated based on female-biased and male-biased gene sets which are consistently sexbiased in at least two ages between PD27, PD32 and PD37 is plotted. Coloured points show TFs which have change in $-\log 10(\mathrm{P}$-value) between sexes which is two standard deviations greater than the mean change in $-\log 10(\mathrm{P}$-value). Red points indicate TFs which are enriched for regulating female-biased genes; blue points indicate TFs which are enriched for regulating malebiased genes. 
bioRxiv preprint doi: https://doi org/10.1101/2022 01.05.475069; this version posted January 6, 2022 The copyright holder for this preprint (which was not certified by peer review) is the author/funder, who has granted bioRxiv a license to display the preprint in perpetuity. It is made available under aCC-BY-NC 4.0 International license.

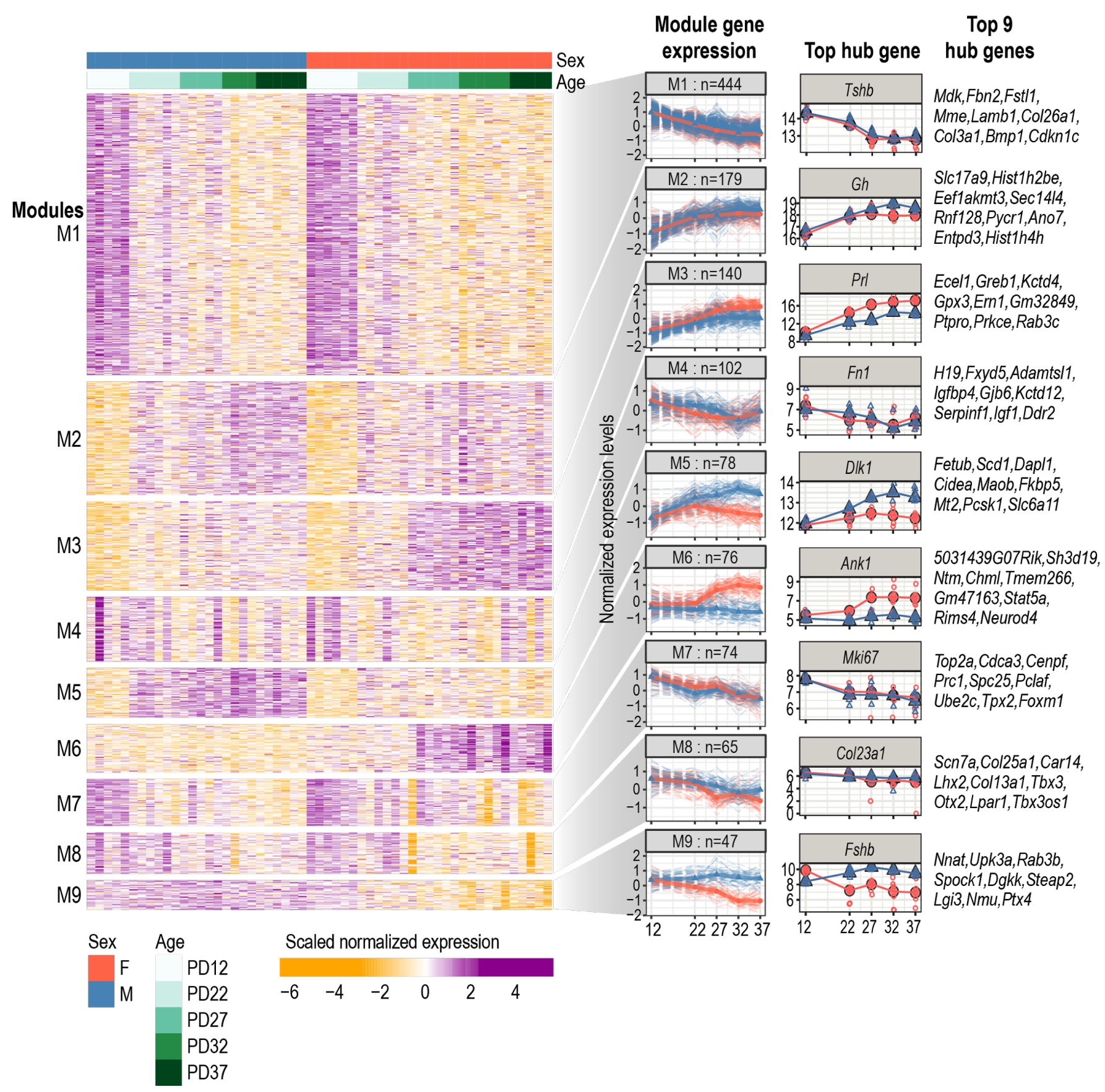

Figure 4. Co-expression network analysis identifies gene modules underlying pituitary transcriptome changes.

Heatmap shows genes selected for co-expression analysis, separated into 9 modules. Column annotation bars indicate sample age and sex. Colors of the heatmap represent row-scaled and centered expression levels of each gene. A summary of the expression profiles of each module is shown in the left column of the right panel. The solid line represents the median expression (scaled and centered as shown in the heatmap) at each age for all the genes in the corresponding module. Dash lines represent the scaled expression profiles of each gene in the module. Module names and number of genes included in the module are labelled. Expression profile (log2- 
transformed normalized counts) of the top hub gene for each module is shown in the right column of the right panel. Large, filled points represent median expression at each age and unfilled points represent each biological replicate. Blue: male samples; red: female samples. The next top 9 hub genes are listed for each module. 
bioRxiv preprint doi: https://doi org/10.1101/2022 01.05.475069; this version posted January 6, 2022. The copyright holder for this preprint (which was not certified by peer review) is the author/funder, who has granted bioRxiv a license to display the preprint in perpetuity. It is made available under aCC-BY-NC 4.0 International license.

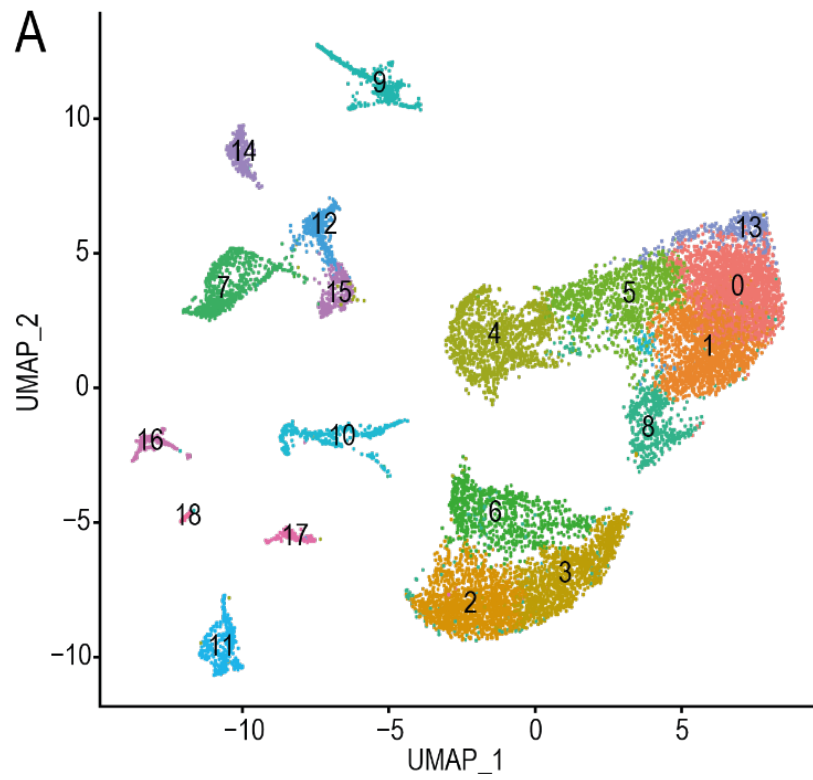

Cell type (Cluster \#)

- Somatotropes $(0,1,4,5,13)$ - Vascular Endothelia (11)

- Lactotropes $(2,3,6)$

- Gonadotropes (7)

- Corticotropes $(12,15)$

- Thyrotropes (9)

- Melanotropes (14)

- Stem cells $($ Sox2+)/FSC (9) Immune cells (17)

- Proliferating (Pou1f1+) (10) - Pituicytes (posterior) (18)
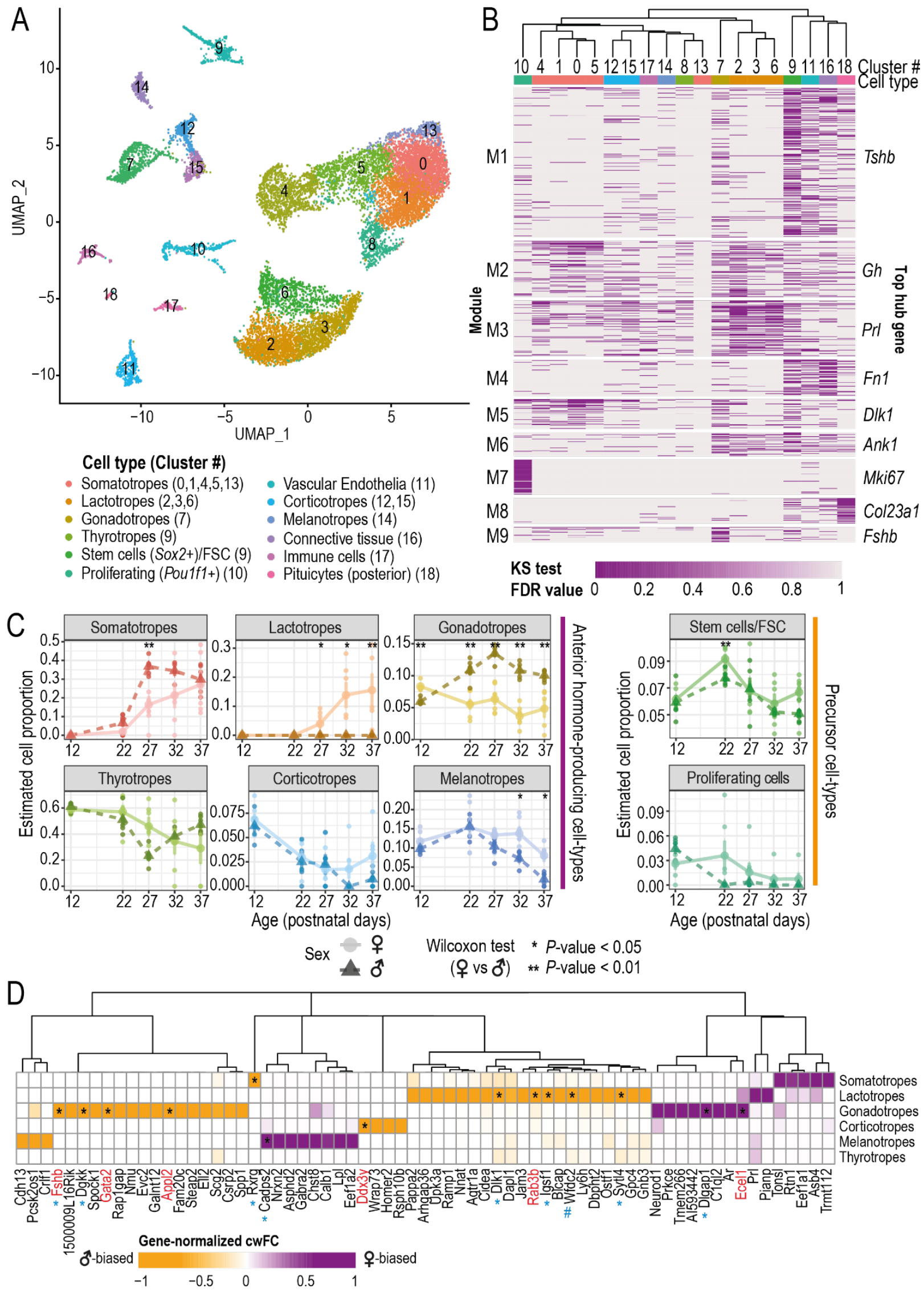
Figure 5. Enrichment of co-expressing modules genes within pituitary cell types which exhibit proportion differences between sexes across postnatal development.

\section{A. Uniform Manifold Approximation and Projection (UMAP) dimension reduction} representation of adult male mouse pituitary gland single-cell transcriptome using unsupervised clustering. 19 clusters were generated from adult male mouse pituitary single cell transcriptome (Cheung et al. 2018) by UMAP dimension reduction using Seurat v3.0 (numbers labelled) (Butler et al. 2018). B. Enrichment heatmap of co-expressing module genes within cell clusters. One-sided Kolmogorov-Smirnov (KS) test was performed for expression of each module gene within a given cell cluster compared to all other cell clusters. Colour gradient represents FDR-adjusted $P$-value for each gene (dark purple: lower FDR $P$-value). Each column represents a cell cluster (labelled at the top by a number). Manual annotation of cell types is shown at the top and denoted by colour. Hierarchical clustering was performed to cluster cell clusters (column). Rows of heatmap are grouped by co-expression gene modules and separated by a break. C. Estimated cell proportion changes across development of hormone-producing and precursor pituitary cell-types from single cell deconvolution. Large points represent mean cell proportion at each age and small points represent each biological replicate. Cell proportions are plotted across profiled postnatal ages. Lighter colour solid line: female samples; dark colour dotted line: male samples. Wilcoxon test was performed to compare cell proportions between both sexes at each age $(* P<0.05, * * P<0.01)$. Only anterior hormone-producing celltypes and precursor cell-types are shown. See Supplementary figure S11 for cell proportions from all identified pituitary cell types. D. Heatmap of gene-normalized cell-weighted foldchanges (cwFC) for hormone-producing cell-type-specific differentially expressed genes. Colour gradient indicates gene-normalized cwFC value calculated by scMappR; purple: femalebiased; orange: male-biased. For each cell type, top 20 genes (based on cwFC) with an absolute gene-normalized cwFC $>0.5$ in at least one hormone-producing cell type are plotted. Asterisks within cells indicate the cell type in which the gene is predicted to be sex-biased. Genes shown to be sex-biased in the same direction in the given cell-type by (Fletcher et al., 2019) are indicated in red text. Blue asterisk denotes sex-biased gene is implicated in pubertal timing by GWAS or pituitary disease. Blue hash denotes gene is found to be sex-biased in the same direction in human pituitary gland by GTEx (Oliva et al., 2020).

Tables

\begin{tabular}{|l|l|l|l|l|l|}
\hline & \multicolumn{1}{|c|}{ PD12 } & \multicolumn{1}{|c|}{ PD22 } & \multicolumn{1}{c|}{ PD27 } & \multicolumn{1}{c|}{ PD32 } & \multicolumn{1}{c|}{ PD37 } \\
\hline \multirow{4}{*}{ Female } & Xist, Lhb, & Xist, Prl, & Xist, Prl, Prkce, & Xist, Akrlc14, Lpl, & Xist, Pcdh11x, Prl, \\
- & Kdm6a, & Kdm6a, & Gm29374, Cdkl4, & Gm47163, Prl, & Gucy2f, Dmrta1, \\
biased & Kcna4, & Greb1, Asb4, & Greb1, Ecel1, & Nrxn3, Pcdh11x, & Cdkl4, Dclk1, \\
& Chrna4, & Cdkl4, Ecel1, & Pcdh10, Ntm, Nav2, & Ntm, Phldb2, Ar, & Akr1c14, Pak7, Chml, \\
& Th & Smyd3, & Nrxn3, Znrf2, & Greb1, Rabgap1l, & Gm29374, Ntm, Ar, \\
\hline
\end{tabular}




\begin{tabular}{|c|c|c|c|c|c|}
\hline & & $\begin{array}{l}\text { Gm29374, } \\
\text { Dok7, } \\
\text { Gucy2f, } \\
\text { Kcnd3, } \\
\text { Gm47163, } \\
\text { Minar1, } \\
\text { Trim9, } \\
\text { Cdkn1c }\end{array}$ & $\begin{array}{l}\text { Gm47163, } \\
\text { F730016J06Rik, } \\
\text { Gucy2f, Gad2, } \\
\text { Pcdh11x, Csrnp3, } \\
\text { Grm5, Phldb2, Asb4, } \\
\text { Ankrd34a, Hmcn1, } \\
\text { Scn11a, Shc2, Rtn1, } \\
\text { Akr1c14, Ar, Thsd7a, } \\
\text { Gm32849, Gm15408, } \\
\text { Pak7, Rxfp1, Chml, } \\
\text { Nhlh2, Kctd4, Pianp, } \\
4933406 B 17 R i k, \\
\text { Ccdc116, Ank1, } \\
\text { Gm15411, } \\
\text { AC121821.1, Dlgap1, } \\
\text { Calb1, Zfp804a, } \\
\text { Pvalb, Fbxo31, Opn3, } \\
\text { Dmrta1, Sh3d19 }\end{array}$ & $\begin{array}{l}\text { Reln, Prkce, Pcdh10, } \\
\text { Cdkl4, Pde7b, Pak7, } \\
\text { Chml, } \\
\text { 4933406B17Rik, } \\
\text { Rxfp1, Crhbp, Nrxn2, } \\
\text { Dennd2a, Chst8, } \\
\text { Tspan7, Ecel1, } \\
\text { Gm21846, Grm5, } \\
\text { Neurod4, Pcdh9, } \\
\text { Cadps2, Apbb1, } \\
\text { Thsd7a, Klhdc8b, } \\
\text { Dmrta1, Hmcn1, } \\
\text { Opn3, Crtac1, Znrf2, } \\
\text { Csrnp3, Nhlh2, } \\
\text { Gucy2f, Rasa4, } \\
\text { Tiam1, Wdr89, } \\
\text { Plppr3, Cryz, } \\
\text { Slc35f1, Pgr }\end{array}$ & $\begin{array}{l}\text { Greb1, Rabgap1l, Id2, } \\
\text { Gm21846, Slc35f1, } \\
\text { Reln, Grm5, Id1, } \\
\text { Kdm6a, Tent5a, } \\
\text { Cadps2, Asb4, Prkce, } \\
\text { Gm47163, Nhlh2, } \\
\text { Hmcn1, } \\
\text { 4933406B17Rik, } \\
\text { Pcdh10, Flrt1, } \\
\text { Phldb2, Sh3d19, } \\
\text { Nrip1, Six6, Neurod4, } \\
\text { Opn3, Ecel1, Rxfp1, } \\
\text { Crhbp, } \\
\text { 5031439G07Rik, Rtn2, } \\
\text { Zfp804a, Il6st, Igf1r, } \\
\text { Ank1, Tmem266, } \\
\text { Ddx3x, Lrp1b }\end{array}$ \\
\hline $\begin{array}{l}\text { Male- } \\
\text { biased }\end{array}$ & $\begin{array}{l}D d x 3 y, \\
\text { Uty, } \\
\text { Gm } 29650 \\
\text { Kdm5d, } \\
\text { Eif } 2 s 3 y, \\
\text { Drd4 }\end{array}$ & $\begin{array}{l}\text { Ddx3y, Uty, } \\
\text { Gm29650, } \\
\text { Kdm5d, } \\
\text { Eif2s3y, } \\
\text { Dgkk, } \\
\text { Gpr101, } \\
\text { Drd4, Nmu, } \\
\text { Pcsk1\#, Ptx4, } \\
\text { Fshb, Nkain1, } \\
\text { Ly6h, } \\
\text { Tspan12, } \\
\text { Fam167b, } \\
\text { Osbp2, Lcn2, } \\
\text { Acadl, } \\
\text { Cyb5r2, } \\
\text { Myo1d, } \\
\text { Serpine2, } \\
\text { Gpd1, } \\
\text { AC117700.1, } \\
\text { Tspan4 }\end{array}$ & $\begin{array}{l}\text { Ddx3y, Uty, } \\
\text { Gm29650, Kdm5d, } \\
\text { Eif2s3y, Drd4, Dgkk, } \\
\text { Gpr101, Nnat, } \\
\text { Pcsk1\#, Ramp3, } \\
\text { Dlk1, Lhb, Ret, Scd1, } \\
\text { Timp1, Dapl1, } \\
\text { Homer2, Cecr2, } \\
\text { Rbp4, Ostf1, Card19, } \\
\text { Chga, Mmp20, Liph, } \\
\text { Fetub, Rab3b, Ptx4, } \\
\text { Atp2b4, Kcnmb4, } \\
\text { Smox, Serpina3c, } \\
\text { Serpine2, Cidea, } \\
\text { Spp1, AC117700.1, } \\
\text { Cd109, Gabre, Nmu, } \\
\text { Cga, Pappa2, } \\
\text { Kcnmb4os2, Nckap1l, } \\
\text { Arhgap36, H2-Eb2, } \\
\text { Th, Gm13889, Cpm, } \\
\text { Jam3, Ell2 }\end{array}$ & $\begin{array}{l}\text { Ddx3y, Uty, } \\
\text { Gm29650, Kdm5d, } \\
\text { Eif2s3y, Dapl1, Nnat, } \\
\text { Gpr101, Dlk1, Drd4, } \\
\text { Scd1, P4ha2, } \\
\text { Arhgap36, Homer2, } \\
\text { Serpine2, Pappa2, } \\
\text { Rab3b, Tacc2, } \\
\text { Galnt16, Rbbp8, } \\
\text { Fads1, Nrip3, Ret, } \\
\text { Fetub, Slc39a14, } \\
\text { Mgat4c, Serpina3c, } \\
\text { Nmnat2, Fkbp5, Lhb, } \\
\text { Arhgef3, Ramp3, } \\
\text { Vangl1, Kcna5, Ptx4, } \\
\text { Dapp1, Ppl, Gabre, } \\
\text { Cidea, Atp2b4, } \\
\text { Smim1, Gh\#, Dgkk, } \\
\text { Aldh1b1, Tspan12, } \\
\text { Tmem52, Car10, } \\
\text { Tmc3, Sytl3, Chga }\end{array}$ & $\begin{array}{l}\text { Ddx3y, Uty, } \\
\text { Gm29650, Kdm5d, } \\
\text { Eif2s3y, Homer2, } \\
\text { Dlk1, Dapl1, } \\
\text { Serpine2, Nnat, } \\
\text { Arhgap36, Gpr101, } \\
\text { Drd4, Atp2b4, Dapp1, } \\
\text { Grb10, Kcnk9, Sytl4, } \\
\text { Fetub, Pappa2, } \\
\text { P4ha2, Mrap2, Scd1, } \\
\text { Aldh1b1, Igsf1\#, } \\
\text { Jam3, Tacc2, Ntrk3, } \\
\text { Lgi3, Tgm2, Deup1, } \\
\text { Galnt10, Ramp3, } \\
\text { Scg2, Nmnat2, } \\
\text { Olfml2b, Chga, } \\
\text { Pcsk2os1, Smim1, } \\
\text { B4galt1, Ddc, } \\
\text { Nckap1l, Fam20c, } \\
\text { Pcsk1\#, Entpd3, } \\
\text { Grip2, Lpin1, Fyb2, } \\
\text { BC039966, Crispld2 }\end{array}$ \\
\hline
\end{tabular}

Table 1. Sex-biased genes at each profiled age ranked by false discovery rate followed by foldchange (capped at 50 genes per comparison). Bolded genes are associated with puberty genomewide association study (GWAS). (\#) denotes genes implicated in pituitary diseases. Bolded and (\#) denotes genes implicated in both puberty GWAS and pituitary diseases.

\begin{tabular}{|l|l|l|l|l|}
\hline & PD12 & \multicolumn{1}{|c|}{ PD22 } & \multicolumn{1}{c|}{ PD27 } & \multicolumn{1}{c|}{ PD32 } \\
\hline Female-biased & novel46 & miR-342-5p & $\begin{array}{l}\text { miR-383-5p, miR-30d-5p, } \\
\text { miR-17-5p }\end{array}$ & $\begin{array}{l}\text { miR-383-5p, miR-205-5p, miR- } \\
\text { 146a-5p, miR-17-5p, miR-485-5p, } \\
\text { miR-30d-5p, novel184, miR-669f-5p }\end{array}$ \\
\hline Male-biased & NA & miR-499-5p & $\begin{array}{l}\text { miR-224-5p, miR-181a-5p, } \\
\text { miR-365-2-5p }\end{array}$ & $\begin{array}{l}\text { miR-224-5p, novel37, miR-871-3p, } \\
\text { miR-30b-5p }\end{array}$ \\
\hline
\end{tabular}


Table 2. Sex-biased miRNAs at each profiled age ranked by false discovery rate followed by foldchange.

\begin{tabular}{|c|c|c|c|c|c|}
\hline & $\begin{array}{l}\text { Gene } \\
\text { name }\end{array}$ & Gene description & $\begin{array}{l}\text { Known pituitary } \\
\text { functions }\end{array}$ & $\begin{array}{l}\text { Mutant pituitary } \\
\text { phenotype }\end{array}$ & References \\
\hline \multirow{5}{*}{ Male-biased } & Cebpd & $\begin{array}{l}\text { CCAAT/enhancer binding } \\
\text { protein }(\mathrm{C} / \mathrm{EBP}) \text {, delta }\end{array}$ & $\begin{array}{l}\text { Suppresses prolactin } \\
\text { expression }\end{array}$ & NA & $\begin{array}{l}\text { (Tong et al., } \\
2011 \text { ) }\end{array}$ \\
\hline & Gata2 & GATA binding protein 2 & $\begin{array}{l}\text { Specification/expansion } \\
\text { of thyrotropes; } \\
\text { maintenance of } \\
\text { hormone production in } \\
\text { gonadotropes and } \\
\text { thyrotropes }\end{array}$ & $\begin{array}{l}\text { Pituitary specific } \\
\text { knockout: decreased } \\
\text { thyrotropes } \\
\text { population at birth; } \\
\text { transient } \\
\text { developmental delay } \\
\text { in males; } \\
\text { lower level of FSH } \\
\text { and TSH in adults }\end{array}$ & $\begin{array}{l}\text { (Charles et al., } \\
2006)\end{array}$ \\
\hline & Gli1 & $\begin{array}{l}\text { GLI-Kruppel family } \\
\text { member GLI1 }\end{array}$ & $\begin{array}{l}\text { Involved in cell } \\
\text { proliferation, hormone } \\
\text { release, CRH signaling } \\
\text { transduction in adult } \\
\text { pituitary }\end{array}$ & NA & $\begin{array}{l}\text { (Pyczek et al., } \\
\text { 2016; Vila et } \\
\text { al., 2005) }\end{array}$ \\
\hline & Hif3a & $\begin{array}{l}\text { hypoxia inducible factor 3, } \\
\text { alpha subunit }\end{array}$ & $\begin{array}{l}\text { Downregulated in } \\
\text { gonadotrope } \\
\text { nonfunctioning pituitary } \\
\text { adenomas }\end{array}$ & NA & $\begin{array}{l}\text { (Kober et al., } \\
2019)\end{array}$ \\
\hline & Zfp $385 a$ & zinc finger protein $385 \mathrm{~A}$ & NA & $\mathrm{NA}$ & \\
\hline Female-biased & $A r$ & androgen receptor & $\begin{array}{l}\text { Regulates LH and FSH } \\
\text { expression and } \\
\text { secretion; } \\
\text { maintains the negative } \\
\text { feedback system of } \\
\text { glucocorticoid } \\
\text { production }\end{array}$ & $\begin{array}{l}\text { Pituitary specific } \\
\text { knockout: lower FSH } \\
\text { serum levels and } \\
\text { reduced LH surge in } \\
\text { female mice; } \\
\text { full knockout: } \\
\text { increased } \\
\text { proopiomelanocortin } \\
\text { (POMC) and } \\
\text { decreased } \\
\text { glucocorticoid } \\
\text { receptor (GR) } \\
\text { expression }\end{array}$ & $\begin{array}{l}\text { (Miyamoto et } \\
\text { al., 2007; Wu } \\
\text { et al., 2014) }\end{array}$ \\
\hline
\end{tabular}




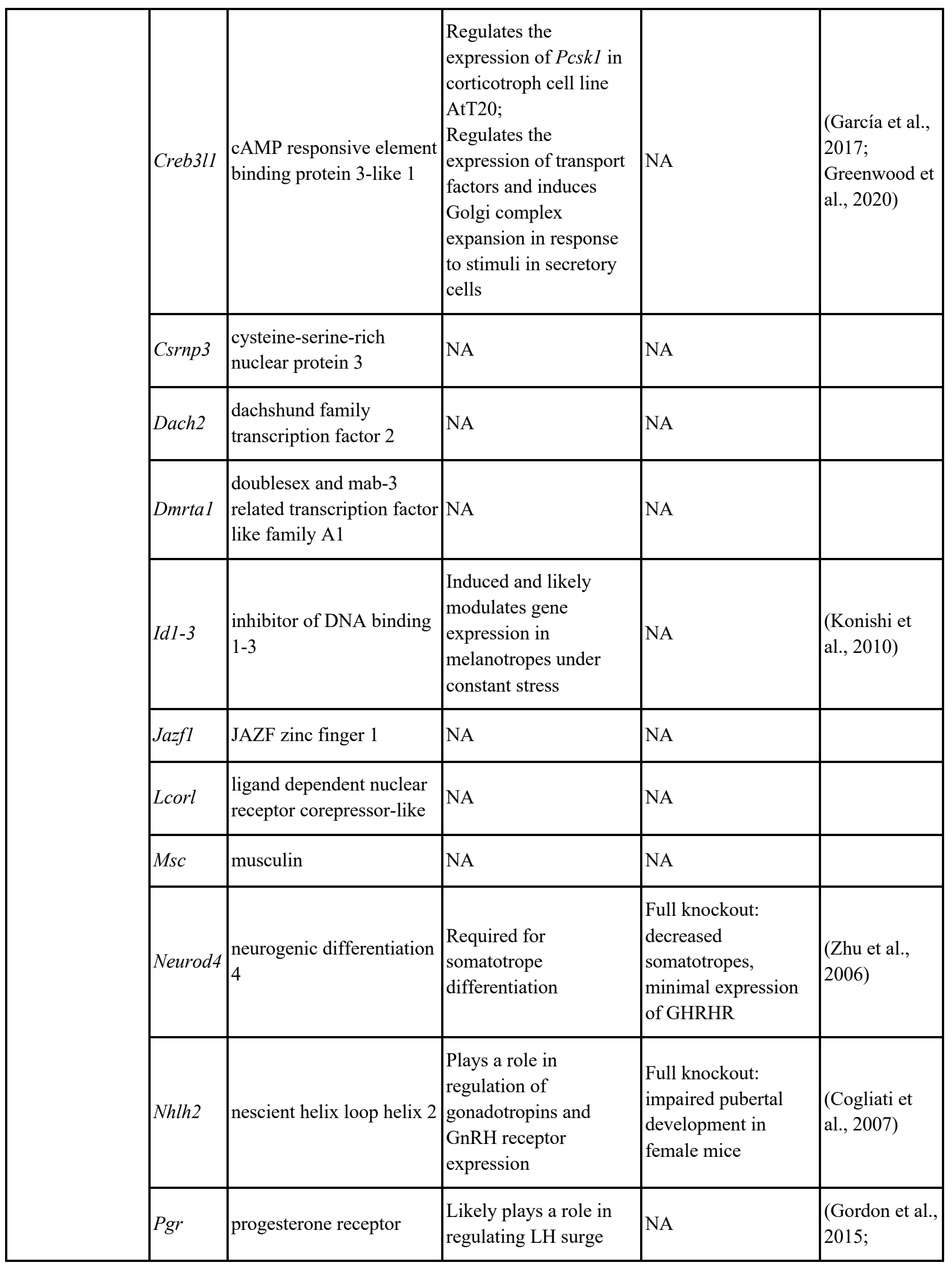




\begin{tabular}{|l|l|l|l|l|l|}
\hline & & & & $\begin{array}{l}\text { Turgeon and } \\
\text { Waring, 2000) }\end{array}$ \\
\cline { 2 - 6 } & Pou $2 f 2$ & $\begin{array}{l}\text { POU domain, class 2 } \\
\text { transcription factor 2 }\end{array}$ & NA & NA & NA \\
\cline { 2 - 6 } & Stat5a & $\begin{array}{l}\text { signal transducer and } \\
\text { activator of transcription } \\
5 \text { A }\end{array}$ & NA & & \\
\hline
\end{tabular}

Table 3. Known pituitary functions and pituitary-related phenotypes of transcription factors that are sex-biased in at least two post-pubertal ages.

\section{References}

Agarwal V, Bell GW, Nam J-W, Bartel DP. 2015. Predicting effective microRNA target sites in mammalian mRNAs. eLife 4. doi:10.7554/eLife.05005

Anbalagan S, Gordon L, Blechman J, Matsuoka RL, Rajamannar P, Wircer E, Biran J, Reuveny

A, Leshkowitz D, Stainier DYR, Levkowitz G. 2018. Pituicyte Cues Regulate the

Development of Permeable Neuro-Vascular Interfaces. Dev Cell 47:711-726.e5.

doi:10.1016/j.devcel.2018.10.017

Andoniadou CL, Matsushima D, Mousavy Gharavy SN, Signore M, Mackintosh AI, Schaeffer

M, Gaston-Massuet C, Mollard P, Jacques TS, Le Tissier P, Dattani MT, Pevny LH,

Martinez-Barbera JP. 2013. Sox2(+) stem/progenitor cells in the adult mouse pituitary

support organ homeostasis and have tumor-inducing potential. Cell Stem Cell 13:433-445.

doi:10.1016/j.stem.2013.07.004

Bak M, Silahtaroglu A, Møller M, Christensen M, Rath MF, Skryabin B, Tommerup N,

Kauppinen S. 2008. MicroRNA expression in the adult mouse central nervous system. RNA

14:432-444. doi:10.1261/rna.783108

Bjelobaba I, Janjic MM, Kucka M, Stojilkovic SS. 2015. Cell Type-Specific Sexual Dimorphism

in Rat Pituitary Gene Expression During Maturation. Biol Reprod 93:21.

doi:10.1095/biolreprod.115.129320

Bottoni A, Zatelli MC, Ferracin M, Tagliati F, Piccin D, Vignali C, Calin GA, Negrini M, Croce

CM, Degli Uberti EC. 2007. Identification of differentially expressed microRNAs by

microarray: a possible role for microRNA genes in pituitary adenomas. $J$ Cell Physiol

210:370-377. doi:10.1002/jcp.20832

Bushnell B. 2014. BBMap: A Fast, Accurate, Splice-Aware Aligner. SourceForge.

Butler A, Hoffman P, Smibert P, Papalexi E, Satija R. 2018. Integrating single-cell transcriptomic data across different conditions, technologies, and species. Nat Biotechnol 36:411-420. doi:10.1038/nbt.4096

Charles MA, Saunders TL, Wood WM, Owens K, Parlow AF, Camper SA, Ridgway EC, Gordon DF. 2006. Pituitary-specific Gata2 knockout: effects on gonadotrope and thyrotrope function. Mol Endocrinol 20:1366-1377. doi:10.1210/me.2005-0378 
Chen Q, Leshkowitz D, Blechman J, Levkowitz G. 2020. Single-Cell Molecular and Cellular Architecture of the Mouse Neurohypophysis. eNeuro 7. doi:10.1523/ENEURO.034519.2019

Cheung LYM, George AS, McGee SR, Daly AZ, Brinkmeier ML, Ellsworth BS, Camper SA. 2018. Single-Cell RNA Sequencing Reveals Novel Markers of Male Pituitary Stem Cells and Hormone-Producing Cell Types. Endocrinology 159:3910-3924. doi:10.1210/en.201800750

Cheung LYM, Rizzoti K, Lovell-Badge R, Le Tissier PR. 2013. Pituitary phenotypes of mice lacking the notch signalling ligand delta-like 1 homologue. J Neuroendocrinol 25:391-401. doi: 10.1111/jne. 12010

Chi SW, Zang JB, Mele A, Darnell RB. 2009. Argonaute HITS-CLIP decodes microRNAmRNA interaction maps. Nature 460:479-486. doi:10.1038/nature08170

Chou C-H, Shrestha S, Yang C-D, Chang N-W, Lin Y-L, Liao K-W, Huang W-C, Sun T-H, Tu S-J, Lee W-H, Chiew M-Y, Tai C-S, Wei T-Y, Tsai T-R, Huang H-T, Wang C-Y, Wu H-Y, Ho S-Y, Chen P-R, Chuang C-H, Huang H-D. 2018. miRTarBase update 2018: a resource for experimentally validated microRNA-target interactions. Nucleic Acids Res 46:D296D302. doi:10.1093/nar/gkx1067

Cogliati T, Delgado-Romero P, Norwitz ER, Guduric-Fuchs J, Kaiser UB, Wray S, Kirsch IR. 2007. Pubertal impairment in Nhlh2 null mice is associated with hypothalamic and pituitary deficiencies. Mol Endocrinol 21:3013-3027. doi:10.1210/me.2005-0337

Collado-Torres L, Nellore A, Frazee AC, Wilks C, Love MI, Langmead B, Irizarry RA, Leek JT, Jaffe AE. 2017. Flexible expressed region analysis for RNA-seq with derfinder. Nucleic Acids Res 45:e9. doi:10.1093/nar/gkw852

Corre C, Shinoda G, Zhu H, Cousminer DL, Crossman C, Bellissimo C, Goldenberg A, Daley GQ, Palmert MR. 2016. Sex-specific regulation of weight and puberty by the Lin28/let-7 axis. J Endocrinol 228:179-191. doi:10.1530/JOE-15-0360

Dauber A, Cunha-Silva M, Macedo DB, Brito VN, Abreu AP, Roberts SA, Montenegro LR, Andrew M, Kirby A, Weirauch MT, Labilloy G, Bessa DS, Carroll RS, Jacobs DC, Chappell PE, Mendonca BB, Haig D, Kaiser UB, Latronico AC. 2017. Paternally inherited DLK1 deletion associated with familial central precocious puberty. J Clin Endocrinol Metab 102:1557-1567. doi:10.1210/jc.2016-3677

Day FR, Bulik-Sullivan B, Hinds DA, Finucane HK, Murabito JM, Tung JY, Ong KK, Perry JRB. 2015. Shared genetic aetiology of puberty timing between sexes and with healthrelated outcomes. Nat Commun 6:8842. doi:10.1038/ncomms9842

Day FR, Thompson DJ, Helgason H, Chasman DI, Finucane H, Sulem P, Ruth KS, Whalen S, Sarkar AK, Albrecht E, Altmaier E, Amini M, Barbieri CM, Boutin T, Campbell A, Demerath E, Giri A, He C, Hottenga JJ, Karlsson R, et al. 2017. Genomic analyses identify hundreds of variants associated with age at menarche and support a role for puberty timing in cancer risk. Nat Genet 49:834-841. doi:10.1038/ng.3841

Dina OA, Aley KO, Isenberg W, Messing RO, Levine JD. 2001. Sex hormones regulate the 
contribution of PKC $\varepsilon$ and PKA signalling in inflammatory pain in the rat. European Journal of Neuroscience 13:2227-2233. doi:10.1046/j.0953-816x.2001.01614.x

Dobin A, Davis CA, Schlesinger F, Drenkow J, Zaleski C, Jha S, Batut P, Chaisson M, Gingeras TR. 2013. STAR: ultrafast universal RNA-seq aligner. Bioinformatics 29:15-21. doi:10.1093/bioinformatics/bts635

Eckstrum KS, Weis KE, Baur NG, Yoshihara Y, Raetzman LT. 2016. Icam5 expression exhibits sex differences in the neonatal pituitary and is regulated by estradiol and bisphenol A.

Endocrinology 157:1408-1420. doi:10.1210/en.2015-1521

Fang Q, George AS, Brinkmeier ML, Mortensen AH, Gergics P, Cheung LYM, Daly AZ, Ajmal A, Pérez Millán MI, Ozel AB, Kitzman JO, Mills RE, Li JZ, Camper SA. 2016. Genetics of Combined Pituitary Hormone Deficiency: Roadmap into the Genome Era. Endocr Rev 37:636-675. doi:10.1210/er.2016-1101

Fauquier T, Lacampagne A, Travo P, Bauer K, Mollard P. 2002. Hidden face of the anterior pituitary. Trends Endocrinol Metab 13:304-309.

Fletcher PA, Smiljanic K, Maso Prévide R, Iben JR, Li T, Rokic MB, Sherman A, Coon SL, Stojilkovic SS. 2019. Cell Type- and Sex-Dependent Transcriptome Profiles of Rat Anterior Pituitary Cells. Front Endocrinol (Lausanne) 10:623. doi:10.3389/fendo.2019.00623

Friedländer MR, Mackowiak SD, Li N, Chen W, Rajewsky N. 2012. miRDeep2 accurately identifies known and hundreds of novel microRNA genes in seven animal clades. Nucleic Acids Res 40:37-52. doi:10.1093/nar/gkr688

García IA, Torres Demichelis V, Viale DL, Di Giusto P, Ezhova Y, Polishchuk RS, Sampieri L, Martinez H, Sztul E, Alvarez C. 2017. CREB3L1-mediated functional and structural adaptation of the secretory pathway in hormone-stimulated thyroid cells. J Cell Sci 130:4155-4167. doi:10.1242/jcs.211102

Gershoni M, Pietrokovski S. 2017. The landscape of sex-differential transcriptome and its consequent selection in human adults. BMC Biol 15:7. doi:10.1186/s12915-017-0352-z

Gordon A, Garrido-Gracia JC, Aguilar R, Sánchez-Criado JE. 2015. Understanding the regulation of pituitary progesterone receptor expression and phosphorylation. Reproduction 149:615-623. doi:10.1530/REP-14-0592

Greenwood M, Paterson A, Rahman PA, Gillard BT, Langley S, Iwasaki Y, Murphy D, Greenwood MP. 2020. Transcription factor Creb311 regulates the synthesis of prohormone convertase enzyme PC1/3 in endocrine cells. J Neuroendocrinol 32:e12851. doi:10.1111/jne.12851

Grimson A, Farh KK-H, Johnston WK, Garrett-Engele P, Lim LP, Bartel DP. 2007. MicroRNA targeting specificity in mammals: determinants beyond seed pairing. Mol Cell 27:91-105. doi:10.1016/j.molcel.2007.06.017

Hao P, Waxman DJ. 2018. Functional Roles of Sex-Biased, Growth Hormone-Regulated MicroRNAs miR-1948 and miR-802 in Young Adult Mouse Liver. Endocrinology 159:1377-1392. doi:10.1210/en.2017-03109

Hauser BM, Lau A, Gupta S, Bi WL, Dunn IF. 2019. The epigenomics of pituitary adenoma. 
Front Endocrinol (Lausanne) 10:290. doi:10.3389/fendo.2019.00290

Hodge CW, Raber J, McMahon T, Walter H, Sanchez-Perez AM, Olive MF, Mehmert K,

Morrow AL, Messing RO. 2002. Decreased anxiety-like behavior, reduced stress hormones, and neurosteroid supersensitivity in mice lacking protein kinase Cepsilon. J Clin Invest

110:1003-1010. doi:10.1172/JCI15903

Hollis B, Day FR, Busch AS, Thompson DJ, Soares ALG, Timmers PRHJ, Kwong A, Easton DF, Joshi PK, Timpson NJ, PRACTICAL Consortium, 23andMe Research Team, Ong KK, Perry JRB. 2020. Genomic analysis of male puberty timing highlights shared genetic basis with hair colour and lifespan. Nat Commun 11:1536. doi:10.1038/s41467-020-14451-5

Ho Y, Hu P, Peel MT, Chen S, Camara PG, Epstein DJ, Wu H, Liebhaber SA. 2020. Single-cell transcriptomic analysis of adult mouse pituitary reveals sexual dimorphism and physiologic demand-induced cellular plasticity. Protein Cell 11:565-583. doi:10.1007/s13238-02000705-X

Hou H, Uusküla-Reimand L, Makarem M, Corre C, Saleh S, Metcalf A, Goldenberg A, Palmert MR, Wilson MD. 2017. Gene expression profiling of puberty-associated genes reveals abundant tissue and sex-specific changes across postnatal development. Hum Mol Genet 26:3585-3599. doi:10.1093/hmg/ddx246

Hughes JN, Aubert M, Heatlie J, Gardner A, Gecz J, Morgan T, Belsky J, Thomas PQ. 2016. Identification of an IGSF1-specific deletion in a five-generation pedigree with X-linked Central Hypothyroidism without macroorchidism. Clin Endocrinol (Oxf) 85:609-615. doi:10.1111/cen.13094

Hu H, Miao Y-R, Jia L-H, Yu Q-Y, Zhang Q, Guo A-Y. 2019. AnimalTFDB 3.0: a comprehensive resource for annotation and prediction of animal transcription factors. Nucleic Acids Res 47:D33-D38. doi:10.1093/nar/gky822

Joustra SD, Schoenmakers N, Persani L, Campi I, Bonomi M, Radetti G, Beck-Peccoz P, Zhu H, Davis TME, Sun Y, Corssmit EP, Appelman-Dijkstra NM, Heinen CA, Pereira AM, Varewijck AJ, Janssen JAMJL, Endert E, Hennekam RC, Lombardi MP, Mannens MMAM, van Trotsenburg ASP. 2013. The IGSF1 deficiency syndrome: characteristics of male and female patients. J Clin Endocrinol Metab 98:4942-4952. doi:10.1210/jc.2013-2743

Joustra SD, Wehkalampi K, Oostdijk W, Biermasz NR, Howard S, Silander TL, Bernard DJ, Wit JM, Dunkel L, Losekoot M. 2015. IGSF1 variants in boys with familial delayed puberty. Eur J Pediatr 174:687-692. doi:10.1007/s00431-014-2445-9

Kim HJ, Gieske MC, Trudgen KL, Hudgins-Spivey S, Kim BG, Krust A, Chambon P, Jeong JW, Blalock E, Ko C. 2011. Identification of estradiol/ER $\alpha$-regulated genes in the mouse pituitary. J Endocrinol 210:309-321. doi:10.1530/JOE-11-0098

Kim VN. 2005. MicroRNA biogenesis: coordinated cropping and dicing. Nat Rev Mol Cell Biol 6:376-385. doi:10.1038/nrm1644

Kober P, Boresowicz J, Rusetska N, Maksymowicz M, Paziewska A, Dąbrowska M, Kunicki J, Bonicki W, Ostrowski J, Siedlecki JA, Bujko M. 2019. The role of aberrant DNA methylation in misregulation of gene expression in gonadotroph nonfunctioning pituitary 
tumors. Cancers (Basel) 11. doi:10.3390/cancers 11111650

Konishi H, Ogawa T, Nakagomi S, Inoue K, Tohyama M, Kiyama H. 2010. Id1, Id2 and Id3 are induced in rat melanotrophs of the pituitary gland by dopamine suppression under continuous stress. Neuroscience 169:1527-1534. doi:10.1016/j.neuroscience.2010.06.030

Kozomara A, Birgaoanu M, Griffiths-Jones S. 2019. miRBase: from microRNA sequences to function. Nucleic Acids Res 47:D155-D162. doi:10.1093/nar/gky1141

Kozomara A, Griffiths-Jones S. 2014. miRBase: annotating high confidence microRNAs using deep sequencing data. Nucleic Acids Res 42:D68-73. doi:10.1093/nar/gkt1181

Kurtoğlu S, Özdemir A, Hatipoğlu N. 2019. Neonatal hypopituitarism: approaches to diagnosis and treatment. J Clin Res Pediatr Endocrinol 11:4-12.

doi:10.4274/jcrpe.galenos.2018.2018.0036

Lau-Corona D, Bae WK, Hennighausen L, Waxman DJ. 2020. Sex-biased genetic programs in liver metabolism and liver fibrosis are controlled by EZH1 and EZH2. PLoS Genet 16:e1008796. doi:10.1371/journal.pgen.1008796

Liao Y, Smyth GK, Shi W. 2014. featureCounts: an efficient general purpose program for assigning sequence reads to genomic features. Bioinformatics 30:923-930. doi:10.1093/bioinformatics/btt656

Lim LP, Lau NC, Garrett-Engele P, Grimson A, Schelter JM, Castle J, Bartel DP, Linsley PS, Johnson JM. 2005. Microarray analysis shows that some microRNAs downregulate large numbers of target mRNAs. Nature 433:769-773. doi:10.1038/nature03315

Ling N, Ying SY, Ueno N, Shimasaki S, Esch F, Hotta M, Guillemin R. 1986. Pituitary FSH is released by a heterodimer of the beta-subunits from the two forms of inhibin. Nature 321:779-782. doi:10.1038/321779a0

Liu B, Shyr Y, Cai J, Liu Q. 2018. Interplay between miRNAs and host genes and their role in cancer. Brief Funct Genomics 18:255-266. doi:10.1093/bfgp/elz002

Li J-T, Xie X-M, Yu J-Y, Sun Y-X, Liao X-M, Wang X-X, Su Y-A, Liu Y-J, Schmidt MV, Wang X-D, Si T-M. 2017. Suppressed Calbindin Levels in Hippocampal Excitatory Neurons Mediate Stress-Induced Memory Loss. Cell Rep 21:891-900. doi:10.1016/j.celrep.2017.10.006

Li R, Vannitamby A, Yue SSK, Handelsman D, Hutson J. 2017. Mouse minipuberty coincides with gonocyte transformation into spermatogonial stem cells: a model for human minipuberty. Reprod Fertil Dev 29:2430-2436. doi:10.1071/RD17100

Lomniczi A, Loche A, Castellano JM, Ronnekleiv OK, Bosch M, Kaidar G, Knoll JG, Wright H, Pfeifer GP, Ojeda SR. 2013. Epigenetic control of female puberty. Nat Neurosci 16:281289. doi:10.1038/nn.3319

Lopes-Ramos CM, Chen C-Y, Kuijjer ML, Paulson JN, Sonawane AR, Fagny M, Platig J, Glass K, Quackenbush J, DeMeo DL. 2020. Sex Differences in Gene Expression and Regulatory Networks across 29 Human Tissues. Cell Rep 31:107795. doi:10.1016/j.celrep.2020.107795

Maliza R, Fujiwara K, Tsukada T, Azuma M, Kikuchi M, Yashiro T. 2016. Effects of retinoic acid on growth hormone-releasing hormone receptor, growth hormone secretagogue 
receptor gene expression and growth hormone secretion in rat anterior pituitary cells. Endocr J 63:555-561. doi:10.1507/endocrj.EJ16-0086

Matthews CH, Borgato S, Beck-Peccoz P, Adams M, Tone Y, Gambino G, Casagrande S, Tedeschini G, Benedetti A, Chatterjee VK. 1993. Primary amenorrhoea and infertility due to a mutation in the beta-subunit of follicle-stimulating hormone. Nat Genet 5:83-86. doi:10.1038/ng0993-83

McCarthy DJ, Chen Y, Smyth GK. 2012. Differential expression analysis of multifactor RNASeq experiments with respect to biological variation. Nucleic Acids Res 40:4288-4297. doi:10.1093/nar/gks042

McCarthy MM, Arnold AP. 2011. Reframing sexual differentiation of the brain. Nat Neurosci 14:677-683. doi:10.1038/nn.2834

Million Passe CM, White CR, King MW, Quirk PL, Iovanna JL, Quirk CC. 2008. Loss of the protein NUPR1 (p8) leads to delayed LHB expression, delayed ovarian maturation, and testicular development of a sertoli-cell-only syndrome-like phenotype in mice. Biol Reprod 79:598-607. doi:10.1095/biolreprod.108.068304

Miyamoto J, Matsumoto T, Shiina H, Inoue K, Takada I, Ito S, Itoh J, Minematsu T, Sato T, Yanase T, Nawata H, Osamura YR, Kato S. 2007. The pituitary function of androgen receptor constitutes a glucocorticoid production circuit. Mol Cell Biol 27:4807-4814. doi:10.1128/MCB.02039-06

Moon AL, Haan N, Wilkinson LS, Thomas KL, Hall J. 2018. CACNA1C: association with psychiatric disorders, behavior, and neurogenesis. Schizophr Bull 44:958-965. doi:10.1093/schbul/sby096

Morgan CP, Bale TL. 2017. Sex differences in microRNA-mRNA networks: examination of novel epigenetic programming mechanisms in the sexually dimorphic neonatal hypothalamus. Biol Sex Differ 8:27. doi:10.1186/s13293-017-0149-3

Newman AM, Liu CL, Green MR, Gentles AJ, Feng W, Xu Y, Hoang CD, Diehn M, Alizadeh AA. 2015. Robust enumeration of cell subsets from tissue expression profiles. Nat Methods 12:453-457. doi:10.1038/nmeth.3337

Nishida Y, Yoshioka M, St-Amand J. 2005a. Sexually dimorphic gene expression in the hypothalamus, pituitary gland, and cortex. Genomics 85:679-687. doi:10.1016/j.ygeno.2005.02.013

Nishida Y, Yoshioka M, St-Amand J. 2005b. The top 10 most abundant transcripts are sufficient to characterize the organs functional specificity: evidences from the cortex, hypothalamus and pituitary gland. Gene 344:133-141. doi:10.1016/j.gene.2004.09.007

O’Brien J, Hayder H, Zayed Y, Peng C. 2018. Overview of microrna biogenesis, mechanisms of actions, and circulation. Front Endocrinol (Lausanne) 9:402. doi:10.3389/fendo.2018.00402

Oishi Y, Okuda M, Takahashi H, Fujii T, Morii S. 1993. Cellular proliferation in the anterior pituitary gland of normal adult rats: influences of sex, estrous cycle, and circadian change.

Anat Rec 235:111-120. doi:10.1002/ar.1092350111

Okonechnikov K, Conesa A, García-Alcalde F. 2016. Qualimap 2: advanced multi-sample 
quality control for high-throughput sequencing data. Bioinformatics 32:292-294. doi:10.1093/bioinformatics/btv566

Oliva M, Muñoz-Aguirre M, Kim-Hellmuth S, Wucher V, Gewirtz ADH, Cotter DJ, Parsana P, Kasela S, Balliu B, Viñuela A, Castel SE, Mohammadi P, Aguet F, Zou Y, Khramtsova EA, Skol AD, Garrido-Martín D, Reverter F, Brown A, Evans P, Stranger BE. 2020. The impact of sex on gene expression across human tissues. Science 369. doi:10.1126/science.aba3066

Ooi GT, Tawadros N, Escalona RM. 2004. Pituitary cell lines and their endocrine applications. Mol Cell Endocrinol 228:1-21. doi:10.1016/j.mce.2004.07.018

Oyola MG, Handa RJ. 2017. Hypothalamic-pituitary-adrenal and hypothalamic-pituitary-gonadal axes: sex differences in regulation of stress responsivity. Stress 20:476-494. doi:10.1080/10253890.2017.1369523

Perez F, Lledo PM, Karagogeos D, Vincent JD, Prochiantz A, Ayala J. 1994. Rab3A and Rab3B carboxy-terminal peptides are both potent and specific inhibitors of prolactin release by rat cultured anterior pituitary cells. Mol Endocrinol 8:1278-1287.

doi:10.1210/mend.8.9.7838160

Perry JR, Day F, Elks CE, Sulem P, Thompson DJ, Ferreira T, He C, Chasman DI, Esko T, Thorleifsson G, Albrecht E, Ang WQ, Corre T, Cousminer DL, Feenstra B, Franceschini N, Ganna A, Johnson AD, Kjellqvist S, Lunetta KL, et al. 2014. Parent-of-origin-specific allelic associations among 106 genomic loci for age at menarche. Nature 514:92-97. doi:10.1038/nature13545

Pyczek J, Buslei R, Schult D, Hölsken A, Buchfelder M, Heß I, Hahn H, Uhmann A. 2016. Hedgehog signaling activation induces stem cell proliferation and hormone release in the adult pituitary gland. Sci Rep 6:24928. doi:10.1038/srep24928

Qiao S, Nordström K, Muijs L, Gasparoni G, Tierling S, Krause E, Walter J, Boehm U. 2016. Molecular Plasticity of Male and Female Murine Gonadotropes Revealed by mRNA Sequencing. Endocrinology 157:1082-1093. doi:10.1210/en.2015-1836

Qin Q, Fan J, Zheng R, Wan C, Mei S, Wu Q, Sun H, Brown M, Zhang J, Meyer CA, Liu XS. 2020. Lisa: inferring transcriptional regulators through integrative modeling of public chromatin accessibility and ChIP-seq data. Genome Biol 21:32. doi:10.1186/s13059-0201934-6

Quirk CC, Seachrist DD, Nilson JH. 2003. Embryonic expression of the luteinizing hormone beta gene appears to be coupled to the transient appearance of $\mathrm{p} 8$, a high mobility grouprelated transcription factor. J Biol Chem 278:1680-1685. doi:10.1074/jbc.M209906200

Risso D, Ngai J, Speed TP, Dudoit S. 2014. Normalization of RNA-seq data using factor analysis of control genes or samples. Nat Biotechnol 32:896-902. doi:10.1038/nbt.2931

Rizzoti K, Akiyama H, Lovell-Badge R. 2013. Mobilized adult pituitary stem cells contribute to endocrine regeneration in response to physiological demand. Cell Stem Cell 13:419-432. doi:10.1016/j.stem.2013.07.006

Robinson AG, Verbalis JG. 2011. Posterior PituitaryWilliams Textbook of Endocrinology. Elsevier. pp. 291-323. doi:10.1016/B978-1-4377-0324-5.00010-9 
Robinson MD, McCarthy DJ, Smyth GK. 2010. edgeR: a Bioconductor package for differential expression analysis of digital gene expression data. Bioinformatics 26:139-140. doi:10.1093/bioinformatics/btp616

Ruby JG, Jan CH, Bartel DP. 2007. Intronic microRNA precursors that bypass Drosha processing. Nature 448:83-86. doi:10.1038/nature05983

Ruf-Zamojski F, Zhang Z, Zamojski M, Smith GR, Mendelev N, Liu H, Nudelman G, Moriwaki M, Pincas H, Castanon RG, Nair VD, Seenarine N, Amper MAS, Zhou X, Ongaro L, Toufaily C, Schang G, Nery JR, Bartlett A, Aldridge A, Sealfon SC. 2021. Single nucleus multi-omics regulatory landscape of the murine pituitary. Nat Commun 12:2677. doi:10.1038/s41467-021-22859-w

Russo PST, Ferreira GR, Cardozo LE, Bürger MC, Arias-Carrasco R, Maruyama SR, Hirata TDC, Lima DS, Passos FM, Fukutani KF, Lever M, Silva JS, Maracaja-Coutinho V, Nakaya HI. 2018. CEMiTool: a Bioconductor package for performing comprehensive modular coexpression analyses. BMC Bioinformatics 19:56. doi:10.1186/s12859-018-2053-1

Sarkar DK, Chaturvedi K, Oomizu S, Boyadjieva NI, Chen CP. 2005. Dopamine, dopamine D2 receptor short isoform, transforming growth factor (TGF)-beta1, and TGF-beta type II receptor interact to inhibit the growth of pituitary lactotropes. Endocrinology 146:41794188. doi:10.1210/en.2005-0430

Sasaki F, Iwama Y. 1988. Sex difference in prolactin and growth hormone cells in mouse adenohypophysis: stereological, morphometric, and immunohistochemical studies by light and electron microscopy. Endocrinology 123:905-912. doi:10.1210/endo-123-2-905

Schang G. 2020. Pituitary mechanisms regulating gonadotropin production and fertility in vivo (Doctoral dissertation). McGill University.

Scheithauer BW, Sano T, Kovacs KT, Young WF, Ryan N, Randall RV. 1990. The pituitary gland in pregnancy: a clinicopathologic and immunohistochemical study of 69 cases. Mayo Clin Proc 65:461-474. doi:10.1016/s0025-6196(12)60946-x

Selbach M, Schwanhäusser B, Thierfelder N, Fang Z, Khanin R, Rajewsky N. 2008. Widespread changes in protein synthesis induced by microRNAs. Nature 455:58-63.

doi: $10.1038 /$ nature07228

Shin S, Kwon O, Kang JI, Kwon S, Oh S, Choi J, Kim CH, Kim DG. 2015. mGluR5 in the nucleus accumbens is critical for promoting resilience to chronic stress. Nat Neurosci 18:1017-1024. doi:10.1038/nn.4028

Sokolowski DJ, Faykoo-Martinez M, Erdman L, Hou H, Chan C, Zhu H, Holmes MM, Goldenberg A, Wilson MD. 2021. Single-cell mapper (scMappR): using scRNA-seq to infer the cell-type specificities of differentially expressed genes. NAR Genom Bioinform 3:lqab011. doi:10.1093/nargab/lqab011

Speert DB, MCClennen SJ, Seasholtz AF. 2002. Sexually dimorphic expression of corticotropinreleasing hormone-binding protein in the mouse pituitary. Endocrinology 143:4730-4741. doi:10.1210/en.2002-220556

Stijnen P, Ramos-Molina B, O'Rahilly S, Creemers JWM. 2016. PCSK1 mutations and human 
endocrinopathies: from obesity to gastrointestinal disorders. Endocr Rev 37:347-371. doi: $10.1210 /$ er.2015-1117

Stinnett GS, Westphal NJ, Seasholtz AF. 2015. Pituitary CRH-binding protein and stress in female mice. Physiol Behav 150:16-23. doi:10.1016/j.physbeh.2015.02.050

Stojilkovic SS, Bjelobaba I, Zemkova H. 2017. Ion channels of pituitary gonadotrophs and their roles in signaling and secretion. Front Endocrinol (Lausanne) 8:126.

doi:10.3389/fendo.2017.00126

Stojilkovic SS, Tabak J, Bertram R. 2010. Ion channels and signaling in the pituitary gland. Endocr Rev 31:845-915. doi:10.1210/er.2010-0005

Taniguchi Y, Yasutaka S, Kominami R, Shinohara H. 2002. Proliferation and differentiation of rat anterior pituitary cells. Anat Embryol 206:1-11. doi:10.1007/s00429-002-0271-8

Tasaka K, Masumoto N, Mizuki J, Ikebuchi Y, Ohmichi M, Kurachi H, Miyake A, Murata Y. 1998. Rab3B is essential for GnRH-induced gonadotrophin release from anterior pituitary cells. J Endocrinol 157:267-274. doi:10.1677/joe.0.1570267

Tong Y, Zhou J, Mizutani J, Fukuoka H, Ren S-G, Gutierrez-Hartmann A, Koeffler HP, Melmed S. 2011. CEBPD suppresses prolactin expression and prolactinoma cell proliferation. $\mathrm{Mol}$ Endocrinol 25:1880-1891. doi:10.1210/me.2011-1075

Topaloğlu AK. 2017. Update on the genetics of idiopathic hypogonadotropic hypogonadism. $J$ Clin Res Pediatr Endocrinol 9:113-122. doi:10.4274/jcrpe.2017.S010

Turgeon JL, Waring DW. 2000. Progesterone regulation of the progesterone receptor in rat gonadotropes. Endocrinology 141:3422-3429. doi:10.1210/endo.141.9.7688

van der Zanden LFM, van Rooij IALM, Feitz WFJ, Knight J, Donders ART, Renkema KY, Bongers EMHF, Vermeulen SHHM, Kiemeney LALM, Veltman JA, Arias-Vásquez A, Zhang X, Markljung E, Qiao L, Baskin LS, Nordenskjöld A, Roeleveld N, Franke B, Knoers NVAM. 2011. Common variants in DGKK are strongly associated with risk of hypospadias. Nat Genet 43:48-50. doi:10.1038/ng.721

Vila G, Papazoglou M, Stalla J, Theodoropoulou M, Stalla GK, Holsboer F, Paez-Pereda M. 2005. Sonic hedgehog regulates $\mathrm{CRH}$ signal transduction in the adult pituitary. FASEB J 19:281-283. doi:10.1096/fj.04-2138fje

Waxman DJ, O'Connor C. 2006. Growth hormone regulation of sex-dependent liver gene expression. Mol Endocrinol 20:2613-2629. doi:10.1210/me.2006-0007

Wei C, Gao J-J. 2019. Downregulated miR-383-5p contributes to the proliferation and migration of gastric cancer cells and is associated with poor prognosis. PeerJ 7:e7882. doi:10.7717/peerj.7882

Wu S, Chen Y, Fajobi T, DiVall SA, Chang C, Yeh S, Wolfe A. 2014. Conditional knockout of the androgen receptor in gonadotropes reveals crucial roles for androgen in gonadotropin synthesis and surge in female mice. Mol Endocrinol 28:1670-1681. doi:10.1210/me.20141154

Yao G, Yin M, Lian J, Tian H, Liu L, Li X, Sun F. 2010. MicroRNA-224 is involved in transforming growth factor-beta-mediated mouse granulosa cell proliferation and granulosa 
cell function by targeting Smad4. Mol Endocrinol 24:540-551. doi:10.1210/me.2009-0432

Ye J, Yao Z, Si W, Gao X, Yang C, Liu Y, Ding J, Huang W, Fang F, Zhou J. 2018.

Identification and characterization of microRNAs in the pituitary of pubescent goats. Reprod Biol Endocrinol 16:51. doi:10.1186/s12958-018-0370-X

Ye R-S, Li M, Qi Q-E, Cheng X, Chen T, Li C-Y, Wang S-B, Shu G, Wang L-N, Zhu X-T, Jiang Q-Y, Xi Q-Y, Zhang Y-L. 2015. Comparative Anterior Pituitary miRNA and mRNA

Expression Profiles of Bama Minipigs and Landrace Pigs Reveal Potential Molecular Network Involved in Animal Postnatal Growth. PLoS ONE 10:e0131987.

doi:10.1371/journal.pone.0131987

Ye Z, Li Z, Wang Y, Mao Y, Shen M, Zhang Q, Li S, Zhou L, Shou X, Chen J, Song Z, Ma Z, Zhang Z, Li Y, Ye H, Huang C, Wang T, He W, Zhang Y, Xie R, Zhao Y. 2015. Common variants at 10p12.31,10q21.1 and 13q12.13 are associated with sporadic pituitary adenoma. Nat Genet 47:793-797. doi:10.1038/ng.3322

Yin M, Lü M, Yao G, Tian H, Lian J, Liu L, Liang M, Wang Y, Sun F. 2012. Transactivation of microRNA-383 by steroidogenic factor-1 promotes estradiol release from mouse ovarian granulosa cells by targeting RBMS1. Mol Endocrinol 26:1129-1143. doi:10.1210/me.20111341

Yoshida S, Kato T, Yako H, Susa T, Cai LY, Osuna M, Inoue K, Kato Y. 2011. Significant quantitative and qualitative transition in pituitary stem/ progenitor cells occurs during the postnatal development of the rat anterior pituitary. $J$ Neuroendocrinol 23:933-943. doi:10.1111/j.1365-2826.2011.02198.X

Yuan B, Han D-X, Dai L-S, Gao Y, Ding Y, Yu X-F, Chen J, Jiang H, Chen C-Z, Zhang J-B. 2015. A comprehensive expression profile of micrornas in rat's pituitary. Int J Clin Exp Med 8:13289-13295.

Yuki KE, Eyck TT, Bannister S, Kyriakopoulou L, Shlien A, Wilson MD. 2018. Automation of the Lexogen QuantSeq3' mRNA Kit on the Agilent NGS Workstation Produces HighQualitySequencing Libraries. Agilent Technologies.

Zhang H, Qi Q, Chen T, Luo J, Xi Q, Jiang Q, Sun J, Zhang Y. 2018. Age-Related Changes in MicroRNA in the Rat Pituitary and Potential Role in GH Regulation. Int J Mol Sci 19. doi:10.3390/ijms19072058

Zhu X, Tollkuhn J, Taylor H, Rosenfeld MG. 2015. Notch-Dependent Pituitary SOX2(+) Stem Cells Exhibit a Timed Functional Extinction in Regulation of the Postnatal Gland. Stem Cell Reports 5:1196-1209. doi:10.1016/j.stemcr.2015.11.001

Zhu X, Zhang J, Tollkuhn J, Ohsawa R, Bresnick EH, Guillemot F, Kageyama R, Rosenfeld MG. 2006. Sustained Notch signaling in progenitors is required for sequential emergence of distinct cell lineages during organogenesis. Genes Dev 20:2739-2753. doi:10.1101/gad.1444706 